\title{
Estudio teórico y experimental sobre los morteros para muros resistentes de fábrica de ladrillo para la actualización de la Norma Básica MV 201-1972
}

\author{
1. ${ }^{a}$ Parte: Memoria del estudio \\ JAVIER LAHUERTA VARGAS, Dr. Arquitecto \\ Catedrático Prof. de la ETSA de NAVARRA \\ GUILLERMO J. MONTERDE COMBA, Dr. Arquitecto \\ Investigador Cientifico. IETCC
}

\section{$R E S U M E N$}

El presente estudio teorico y' experimental sobre morteros, de cemento o de cal y cemento, constituye la puesta al dia del contenido del Capitulo 3 MORTEROS, de la Norma MV 20I-1972 "Muros resistentes de fábrica de ladrillo", que ferdio su vigencia con la desaparicion del cemento portland P-250, sustituido por el cemento portland PA-350 con adiciones activas prescrito en el nuevo Pliego $R C-75$ "Pliego de prescripciones técnicas generales para la recepcion de cementos" de obligado cumplimiento.
$S U M M A R Y$

This theoretical and experimental study on cement or lime and cement mortars brings up to date the contents of Chapter 3: MORTARS, of Norm MV 201-1972 "Resistant brick-work walls" which lost its validity when disapeared portland cement P-250, substituted by portland cement PA-350 whith active additions, prescribed in the new Standard $R C-75$ "Standard of general technical prescriptions for cements acceptance" being obligatory its fulfilment.

\section{ALCANCE DEL ESTUDIO}

\subsection{Introducción}

La dirección General de Arquitectura y Vivienda del ministerio de Obras Públicas y Urbanismo planteó la revisión de la Norma básica MV 201-1972, Muros resistentes de fábrica de ladrillo, (1), creando una Comisión que se constituyó el 6 de julio de 1981, presidida por el Subdirector General de Edificación D. Luis Felipe Rodriguez Martin, y compuesta por representantes de Ministerios, Colegios profesionales, Asociaciones Empresariales, Institutos de Normalización e Investigación, y otras Organizaciones interesadas en la normativa de los muros de fábrica de ladrillo.

El representante en esta Comisión del Instituto Eduardo Torroja de la Construcción y del Cemento, IETcc, D. Guillermo Monterde Comba, señaló en la reunión del dia 27 de enero de 1982 que el contenido del Capitulo 3, Morteros, de la Norma MV 201-1972, venia muy influido por la variación de caracteristicas de los cementos españoles, que se produjo al promulgar el Pliego RC-75, Prescripciones generales para la recepción de cementos (2), con modificaciones esenciales respecto de las del Pliego de 1964, vigente en la fecha de promulgación de la Norma 201-1972.

F.l representante del IETec expuso la necesidad de realizar un estudio experimental sobre morteros para fábricas. confeccionados con el cemento PA-350, de uso generalizado en la actualidad. y que ha sustituido al cemento P-250, que era el de empleo común anteriormente, y 
manifestó que su Instituto estaba en condiciones de realizar este trabajo experimental, con la colaboración del Laboratorio de Edificación de la Escuela Técnica Superior de Arquitectura de la Universidad de Navarra, lo que fue confirmado por D. Javier Lahuerta Vargas, Director de dicho Laboratorio y miembro asimismo de la Comisión. La Comisión antes citada manifestó su acuerdo con lo expuesto y con la realización del trabajo experimental.

El presente trabajo que ha sido llevado a cabo por el Laboratorio de Edificación, por encargo, bajo las directrices, y financiado por el Instituto Eduardo Torroja, complementará al que tiene intención de realizar el IETcc estudiando la hidrofilia, o retentividad del agua de amasado de los morteros frescos, la influencia del contenido de aire, y otros temas.

\subsection{Plan general}

El Instituto Eduardo Torroja de la Construcción y del Cemento y el Laboratorio de Edificación trataron de la cuestiones que deberian estudiarse para la actualización del Capitulo 3, Morteros de la Norma Básica MV 201-1972, y establecieron los criterios generales de actuación.

Para programar los trabajos y supervisar su realización, se constituyó en la Escuela Técnica Superior de Arquitectura de la Universidad de Navarra un Grupo de Trabajo, con los siguientes miembros:

D. Javier Lahuerta Vargas, Prof. Dr. Arquitecto, Director del Departamento de Estructuras, y del Laboratorio de Edificación.

D. Juan Lahuerta Vargas, Prof. Dr. Arquitecto, Director del Departamento de Construcción.

D. Domingo Pellicer Daviña, Dr. Arquitecto, Profesor adjunto del Departamento de Construcción.

D. Lorenzo García Durán, Dr. Arquitecto, Jefe de Sección del Laboratorio de Edificación.

D. Miguel Angel Gutiérrez Fernández, Arquitecto, Ayudante del Departamento de Construcción.

D. Francisco Zuasti Elizondo, Arquitecto, Ayudante del Departamento de Construcción.

El Grupo de Trabajo redactó primeramente una propuesta de los trabajos teóricos y experimentales que realizaría el Laboratorio de Edificación. Esta propuesta se envió y fue aprobada por el IETcc, en la forma en que figura en 1.3. El grupo de Trabajo designó al Sr. Zuasti encargado de la puesta en marcha y realización de los trabajos.

\subsection{Programa de los trabajos}

La propuesta citada en 1.2, de los trabajos teóricos y experimentales encargados al laboratorio de Edificación es la que se indica a continuación, relacionando los trabajos bajo los números de los articulos del actual Capítulo 3, Morteros, de la Norma Básica MV 201-1972.

\section{“3.1. Condiciones de los materiales}

\section{“3.1.1. Cemento}

Redacción de una nueva Tabla 3.1. recomendaciones para el empleo de distintos tipos de cemento en la confección del mortero para muros de fábrica de ladrillo, adaptada al vigente Pliego RC-75, Prescripciones técnicas generales para la recepción de cementos. 


\section{“3.1.2. Cales}

Investigación de las cales que existen en el mercado español. Revisión de la Tabla 3.2. Condiciones de las cales aéreas a la vista de los datos suministrados por los fabricantes.

Revisión de la Tabla 3.3. Condiciones de las cales hidráulicas.

\section{“3.1.3. Arenas}

Investigación experimental sobre la influencia del contenido de finos de la arena en la resistencia del mortero, con distinción de arcilla y limo, mediante la determinación del denominado equivalente de arena.

Propuesta de limitación del contenido de finos a la vista de los resultados de la investigación.

Propuesta sobre la limitación del tamaño máximo de los granos.

Propuesta sobre limites del contenido máximo de impurczas.

\section{"3.1.4. Agua de amasado}

Revisión del condicionado actual.

\section{“3.1.5. . Aditivos}

Propuesta de condiciones exigibles a los aditivos: D.I.T. y otros.

\section{“3.2. Características de los morteros}

\section{“3.2.1. Dosificación}

Propuesta estableciendo la dosificación en peso, lo que es ya práctica bastante generalizada, y una equivalencia en volumen para obras poco mecanizadas.

\section{“3.2.2. Resistencia}

Investigación experimental de las resistencias que se obtienen con unas dosificaciones tipo, establecidas en peso, deducidas de las que figuran en la Tabla 3.5. Dosificación de los morteros tipo, con cemento PA-350 que es el actualmente usual.

Propuesta de Tabla 3.5. manteniendo la nomenclatura y gradación actual de resistencias, probablemente con supresión de uno de los dos escalones inferiores. No parece conveniente incluir un escalón superior a M-160 innecesario para los ladrillos que se fabrican.

\section{“3.2.3. Plasticidad}

Esta es una propiedad del mortero, importante para el asentamiento del ladrillo, pero cuya medición no figura en ninguna Norma. Se estudiará a fondo esta cuestión con el fin de precisar un poco más la definición actual. Se ignora si podrán obtenerse resultados utilizables". 


\subsection{Esquema documental}

El conjunto de los trabajos teóricos y experimentales realizados se definen en los siguientes documentos:

Memoria, que recoge la descripción general de los trabajos en conjunto y en detalle, las razones por las que se han realizado y una sintesis de los resultados experimentales obtenidos.

Propuesta, de revisión del Capítulo 3, Morteros, de la Norma Básica MV 201-1972, Muros resistentes de fábrica de ladrillo, que ha redactado el Grupo de Trabajo, basándose en estudios teóricos y en los resultados de los trabajos.

Anejo 1. Descripción de los aparatos, métodos de ensayo y Normas que se han empleado en la realización de los ensayos.

Anejo 2. Recopilación completa de los resultados de los ensayos realizados sobre los materiales empleados en la fabricación de los morteros.

Anejo 3. Recopilación y resúmenes de los resultados de los ensayos realizados sobre los morteros.

\section{CAPITULO 2. ESTUDIO DE LOS MATERIALES}

\subsection{Generalidades}

Todos los materiales empleados en la confección de morteros para fábricas han sido objeto del estudio, aunque con diferente tratamiento según sus peculiaridades, teniendo en cuenta la Norma MV 201-1972 (1), el Pliego RC-75, (2) y los Pliegos de Condiciones para la ejecución de fábricas de ladrillo vigentes (3). (4) o recomendatorios (5).

En los epigrafes sucesivos se detallan los estudios realizados con cada uno de los materiales:

\subsection{Cementos.}

2.3. Cales.

2.4. Arenas.

2.5. Arenas compuestas.

2.6. Aguas de amasado.

\subsection{Aditivos.}

Los resultados de los ensayos realizados en cada uno de ellos se reflejan detalladamente en el Anejo 2. Estos resultados han sido analizados por el Grupo de Trabajo, quien ha redactado la Propuesta de revisión del Capitulo 3. Morteros, de la Norma MV 201-1972.

\subsection{Cementos}

En la confección de morteros para muros resistentes de fábrica de ladrillo se usa actualmente en la mayoría de los casos el cemento portland con adiciones activas PA-350.

Este tipo de cemerito ha sustituido al cemento portland P-350, que podria denominarse ordinario, pero que no se fabrica actualmente por varias razones, entre ellas la de ahorro de combustible (6). 
En el Pliego RC-75 figura el cemento compuesto C-200, que puede contener adiciones inertes en proporción no superior al $35 \%$ en peso. Este tipo de cemento parece haber sido establecido como cemento de albañileria; sin embargo, no se fabrica actualmente, y por consiguiente no se emplea.

Los demás tipos de cemento apenas son usados, salvo en ámbitos muy restringidos, exceptuándose aquellos casos en que se necesitan propiedades especiales, cuyo número es muy pequeño.

Los morteros de este trabajo han sido realizados todos ellos con cemento PA-350, marca El Cangrejo, fabricado por Cementos Portland S. A., Olazagutia (Navarra), procedente de una sola remesa y conservado en recipientes herméticos de plástico.

Las caracteristicas de este cemento, según los ensayos normales del Pliego RC-75, figuran en el Anejo 2 de este Estudio.

El Grupo de Trabajo hizo una nueva redacción del Artículo 3.1.2., Cementos, del Capitulo 3 de la Norma MV 201, recogiendo condiciones relativas a recepción y almacenamiento, y estudió la Tabla de recomendaciones para el empleo de distintos tipos de cemento en la confeccion del mortero para muros de fábrica de ladrillo. considerando las opiniones emitidas (7), (8), (9).

El criterio seguido en la redacción de esta Tabla ha sido el de incluir todos los tipos y categorias de cemento, aunque actualmente no se fabriquen, y los cementos con propiedades adicionales.

Finalmente el Grupo de Trabajo estimó que el contenido de dicha Tabla no constituia en general condiciones de Norma, y por esta razón se ha pasado al Apéndice A de la Norma, que no tiene carácter prescriptivo.

\subsection{Cales}

El consumo de cales para la confección de morteros para fábricas en España es en la actualidad muy escaso.

Los morteros cuyo conglomerante es sólo cal aérea, no se emplean actualmente; los de cemento y cal aérea se confeccionan en algunos casos, utilizándose la cal para mejorar la plasticidad del mortero y hacer más claro su color. Los morteros de cal hidráulica se emplean solamente en zonas de alrededor de las escasas fábricas que producen este conglomerante.

Las recomendaciones CIB (10), y las normas extranjeras (11), (12), (13), (14), (15), (16), incluyen siempre morteros de cemento y cal, y en general exigen emplear cal cuando la relación en volumen cemento : arena es inferior a $1: 4$.

Se pidió a fabricantes de cal enviasen datos sobre las caracteristicas de sus productos, y muestras para realizar ensayos. Se recibieron las contestaciones que se indican en el Cuadro 1.

En el laboratorio se determinaron en cada muestra de cal las siguientes características:

Carácteres organolépticos: color, tacto.

Peso especifico aparente de la cal suelta, en polvo o en terrón.

Contenido de óxido cálcico UNE 7095

Contenido de óxido magnésico UNE 7095 
Pérdida por calcinación

UNE 7099

Contenido de anhidrido carbónico UNE 7099

Contenido total de agua

UNE 7099

Finura

UNE 7187 y UNE 7190

Residuo en tamiz 0,2

UNE 7050

Residuo en tamiz 0,08

UNE 7050

CUADRO 1

Contestaciones de fabricantes de cal

\begin{tabular}{|c|c|c|c|}
\hline Fabricante & \begin{tabular}{|l|} 
Linvian \\
caracte- \\
rísticas
\end{tabular} & \begin{tabular}{|l|} 
Número \\
asignado \\
a la \\
muestra
\end{tabular} & Clase de cal \\
\hline Hijo de Fernando Roca & $S j$ & No envió & Cal aérea apagada en polvo \\
\hline Moilins de Rey (Barcelona) & No & No envió & Cal hidráulica \\
\hline $\begin{array}{l}\text { Cal Industrial S.A. } \\
\text { Tiebas (Navarra) }\end{array}$ & Si & 4 & $\begin{array}{l}\text { Cal aérea ajacjada en polvo } \\
\text { No fabrica cal hidráulica }\end{array}$ \\
\hline $\begin{array}{l}\text { Cales Pascual S.L: } \\
\text { Paterna (Valencia) }\end{array}$ & Si & 1 & $\begin{array}{l}\text { Cal aerea apagada on polvo } \\
\text { No fabrica cal hidréulica }\end{array}$ \\
\hline Cales de Pachs S.A. & Si & 3 & Cal aerea viva en polvo \\
\hline Pachs del Panadés (Barcelona) & $\mathrm{Si}$ & 7 & $\begin{array}{l}\text { Cal aérea apagada en pclvo } \\
\text { No fabrica cal hidráulica }\end{array}$ \\
\hline $\begin{array}{l}\text { Uerivados Cálcicos S.A. } \\
\text { Gerona }\end{array}$ & $\mathrm{Si}$ & 2 & $\begin{array}{l}\text { Cal aérea apajaciai on polvo } \\
\text { No fabrica cal hidráulica }\end{array}$ \\
\hline $\begin{array}{l}\text { Fidel Azcábide S.A. } \\
\text { Alzo (Guipúzcoa) }\end{array}$ & No & 5 & $\begin{array}{l}\text { Cal aérea asacjacia en polvo } \\
\text { No fabrica cül hidráulica }\end{array}$ \\
\hline $\begin{array}{l}\text { Tudela Lafargue S.A. } \\
\text { Tudela Veguin (Asturias) }\end{array}$ & $\mathrm{Si}$ & 6 & $\begin{array}{l}\text { Cal aérea viva en terréi } \\
\text { No fabrica cal hidráulica }\end{array}$ \\
\hline
\end{tabular}

Para comprobar el cumplimiento de las exigencias de la Norma MV 201 se calcularon los siguientes contenidos referidos al peso total, menos el peso del agua contenida:

- Contenido de óxidos cálcico y magnésico.

- Contenidos de anhídrido carbónico.

Los resultados de los ensayos figuran en el Anejo 2 de este estudio, y se resumen en el Cuadro 2. 
CUADRO 2

Resultados de los ensayos de las cales aéreas

\begin{tabular}{|c|c|c|c|c|c|c|}
\hline \multicolumn{2}{|c|}{ Muestra de cal aérea } & \multicolumn{2}{|c|}{ Contenicio de } & \multicolumn{3}{|c|}{$\begin{array}{l}\text { Peso espe- Resiciuo en tamiz(I) } \\
\text { Cífico apa }\end{array}$} \\
\hline$n^{2}$ & Suministro & $\begin{array}{c}\mathrm{CaO}+\mathrm{IIgO} \\
\frac{0}{8}\end{array}$ & $\begin{array}{c}\mathrm{CO}: \\
\vdots \\
\vdots\end{array}$ & $\begin{array}{l}\text { rente } \\
\mathrm{Mp} / \mathrm{m}^{3}\end{array}$ & $\begin{array}{c}0,2 \\
8 \\
\end{array}$ & $\begin{array}{c}0,08 \\
8 \\
8\end{array}$ \\
\hline 1 & Apagada en polvo & 91,0 & 7,9 & 0,41 & 0,4 & 1,0 \\
\hline 2 & Apagada en polvo & 87,1 & 8,5 & 0,36 & 0,4 & 2,2 \\
\hline 3 & Viva en polvo & 96,5 & 3,4 & 0,71 & 0 & 0,8 \\
\hline 4 & Apagada en polvo & 93,3 & 5,3 & 0,38 & 0,2 & 0,2 \\
\hline 5 & Apagada en polvo & 90,4 & 7,6 & 0,43 & 0,2 & 1,7 \\
\hline 6 & Viva en terrón & 97,1 & 1,5 & 1,05 & 10,4 & 13,0 \\
\hline 7 & Apagada en polvo & 94,3 & 2,2 & 0,34 & 0 & 0 \\
\hline (1) & $\begin{array}{l}\text { Como residuo en e } \\
\text { el de } 0,2 \text {. }\end{array}$ & niz 0 & se & el val & & con \\
\hline
\end{tabular}

No se recibio ninguna muestra de cal hidráulica. Su consumo es realmente escaso.

El Grupo de Trabajo, a la vista de estos resultados tomó las siguientes decisiones relativas a las propuestas de revisión del Capítulo 3.

Dividir el actual Artículo 3.1.2. en dos. Uno referente a las cales aéreas y otro a cales hidráulicas.

Redactar el referente a cales aéreas adaptándolo a las condiciones actuales de su suministro, y establecer siglas para los tipos.

Modificar la Tabla 3.2. para que sin ambigüedad sus prescripciones puedan aplicarse a las cales vivas y a las cales apagadas, lo que no está claro en la actual.

Rebajar la exigencia del tipo CA.2 en lo referente al contenido de $\mathrm{CO}_{2}$, no cumplido actualmente, y que en el empleo para morteros no es decisivo.

En el referente a las cales hidráulicas se propone reducir a dos los tres tipos actuales, ya que la escasa producción no justifica mantener más que una cal hidráulica de primera calidad, y otra de calidad mínima.

Modificar la Tabla 3.3 ajustándola a estos criterios. La resistencia debe actualmente obtenerse mediante la Norma UNE 7205, sobre barras de $4 \times 4 \times 16 \mathrm{~cm}^{3}$, determinando las resistencias a flexotraccion y compresión. Los valores prescritos en esta Tabla a flexotracción se han obtenido comparativamente y deberán ser verificados experimentalmente.

\subsection{Arenas}

Para conocer las caracteristicas de las arenas que se emplean actualmente en la confección de morteros para fábricas de ladrillo, se encargó a doce arquitectos, de doce localidades españolas, que tomasen muestras de arenas comúnmente empleadas para la confección de morteros para fábricas de ladrillo, y las remitiesen al Laboratorio para su ensayo.

Se dispuso de las doce muestras que se indican en el Cuadro 3. 
CUADRO 3

Muestras de arenas recibidas

\begin{tabular}{|r|l|l|}
\hline If & \multicolumn{1}{|c|}{ Procedencia } & Origen \\
\hline 1 & Barcelona & Natural, de rio \\
2 & Gerona & Natural, de rio \\
3 & Leon & Natural, de rio \\
4 & Madrid & Natural, de rio \\
5 & Alicante & Natural, de mina \\
6 & Lodosa (Navarra) & Natural, de cantera \\
7 & Tudela (Navarra) & Natural, de cantera \\
8 & San Sebastián & Natural, de playa \\
9 & Sevilla & Natural, de plaýa fluvial \\
10 & Vigo (Fonteveara) & Natural, de playa \\
11 & Granada & Machaqueo \\
12 & Tiebas (Navarra) & Machayueo \\
\hline
\end{tabular}

Con ellas se realizaron los ensayos que se indican a continuación, reseñando la Norma aplicada:

- Contenido de finos, UNE 7135.

- Contenido de materia orgánica, UNE 7082.

- Contenido de compuestos de azufre, UNE 7245.

- Granulometria UNE 7139, y módulo granulométrico.

Forma de los granos:

- Peso especifico de la arena suelta y de la arena compactada. Compacidad, UNE 7088.

- Equivalente de arena, UNE 7324, preparando la muestra según UNE 7327.

- Reactividad potencial con álcalis del cemento, UNE 7137.

Los resultados de estos ensayos figuran en el Anejo 2 de este Estudio, y se resumen en los cuadros 4 y 5 .

La linea granulométrica de las 12 arenas se representa en la figura 1 . La línea granulométrica de la fracción $<2,5 \mathrm{~mm}$ de dichas arenas se representa en la figura 2 .

Por el modo de adquisición de las arenas, y su localización geográfica, el conjunto puede considerarse como una muestra representativa de las arenas que se están empleando en la Peninsula. El grado de cumplimiento de las condiciones que exigen la actual Norma MV 2011972, o que se deriven de ellas, se refleja en el Cuadro 6.

Estos resultados han sido estudiados por el Grupo de Trabajo, y contrastados con su experiencia constructiva, llegando a las conclusiones siguientes en relación con las condiciones que deberian exigirse en la Norma: 
CUADRO 4

Resultados de los ensayos de las arenas

\begin{tabular}{|c|c|c|c|c|c|c|c|c|c|}
\hline \multirow{2}{*}{\multicolumn{2}{|c|}{$\begin{array}{l}\text { Arena } \\
\text { ne Clase }\end{array}$}} & \multirow{2}{*}{$\begin{array}{l}\text { Forma } \\
\text { de los } \\
\text { granos }\end{array}$} & \multicolumn{2}{|c|}{$\begin{array}{l}\text { Peso especifico } \\
\text { aparente }\end{array}$} & \multirow{2}{*}{$\begin{array}{c}\text { Compa- } \\
\text { cidad } \\
\text { i }\end{array}$} & \multirow{2}{*}{$\begin{array}{c}\text { Tinos } \\
\text { \% }\end{array}$} & \multirow{2}{*}{$\begin{array}{l}\text { Materia } \\
\text { orcjsinica }\end{array}$} & \multirow{2}{*}{$\begin{array}{l}\text { Cornuestos } \\
\text { de azufre } \\
\mathrm{SU}_{4}^{-} \\
\frac{0}{8}\end{array}$} & \multirow{2}{*}{$\begin{array}{l}\text { Reactivi } \\
\text { dad poten } \\
\text { cial }\end{array}$} \\
\hline & & & $\begin{array}{l}\text { Suelta } \\
\qquad \mathrm{m} / \mathrm{m}^{3}\end{array}$ & $\begin{array}{c}\text { Cormpacta } \\
\mathrm{M} / \mathrm{m}^{3}\end{array}$ & & & & & \\
\hline & RIO & Polied. & 1,47 & 1,64 & 65 & 1,2 & Aăñ & 0,01 & No \\
\hline & 2 RIO & Polied. & 1,48 & 1,68 & 61 & 4,6 & Acim. & 0,05 & No \\
\hline 3 & 3 RIO & Polied. & 1,65 & 1,91 & 74 & 6,5 & Adm. & 0,01 & No \\
\hline 4 & Rio & Polied. & 1,48 & 1,67 & 65 & 4,5 & Adm. & 0,10 & No \\
\hline 5 & Mina & Polied. & 1,39 & 1,66 & 65 & 29,3 & Adm. & 0,10 & No \\
\hline 6 & ; Cantera & Polied. & 1,45 & 1,69 & 70 & 21,2 & Adm. & 0,01 & No \\
\hline 7 & Cantera & Polied. & 1,62 & 1,90 & 74 & 14,0 & Idm. & 0,10 & No \\
\hline 8 & Playa & Redond. & 1,21 & 1,38 & 56 & 5,4 & Adm. & 0,44 & No \\
\hline 9 & Playa F. & Redond. & 1,31 & 1,53 & 60 & 12,7 & Adm. & 0,09 & No \\
\hline 10 & Playa & Redond. & 1,36 & 1,57 & 62 & 2,3 & Inad. & 0,18 & No \\
\hline 11 & Machaq. & Polied. & 1,51 & 1,91 & 71 & 20,4 & Adm. & 0,34 & No \\
\hline 12 & Machaq. & Polied. & 1,47 & 1,97 & 74 & 25,1 & Adrit. & 0,12 & No \\
\hline
\end{tabular}

CUADRO 5

Resultados de la granulometria de las arenas

\begin{tabular}{|c|c|c|c|c|c|c|c|c|}
\hline \multirow{2}{*}{$\begin{array}{l}\text { Arena } \\
\text { ne Clase }\end{array}$} & \multirow{2}{*}{$\begin{array}{l}\text { Equiva- } \\
\text { lente de } \\
\text { arena } \\
\frac{8}{8}\end{array}$} & \multicolumn{6}{|c|}{ Retencion en peso en el tamiz (mm): } & \multirow{2}{*}{$\begin{array}{l}\text { Modulc } \\
\text { yranulo- } \\
\text { rstrice }\end{array}$} \\
\hline & & $\begin{array}{l}5 \\
80\end{array}$ & $\begin{array}{c}2,5 \\
0 \\
0\end{array}$ & $\begin{array}{c}1,<5 \\
\%\end{array}$ & $\begin{array}{c}0,63 \\
:\end{array}$ & $\begin{array}{c}0,32 \\
\frac{\circ}{0} .\end{array}$ & 0,16 & \\
\hline 1 RIO & 97 & 99,7 & 86,1 & 53,8 & 23,5 & 6,2 & 2,2 & 3,29 \\
\hline 2 RIO & 89 & 99,8 & 97,0 & $\varepsilon 6,9$ & 65,5 & 23,1 & 7,4 & 3,16 \\
\hline 3 RIO & 87 & 89,6 & 70,8 & 57,1 & 42,2 & 18,2 & 8,8 & 3,13 \\
\hline 4 RIO & 90 & 99,6 & 88,1 & 70,9 & 44,1 & 12,3 & 6,0 & 2,79 \\
\hline 5 Mina & 28 & 99,8 & 92,2 & 81,7 & 72,7 & 58,3 & 42,5 & 1,53 \\
\hline 6 Cantera & 29 & 99,4 & 97,8 & 95,4 & 90,3 & 66,0 & 35,9 & 1,15 \\
\hline 7 Cantera & 62 & 93,8 & 75,4 & 63,7 & 56,9 & 35,4 & $20, j$ & 2,55 \\
\hline 8 Playa & 90 & 98,9 & 96,7 & 93,2 & 88,2 & 63,4 & 19,3 & 1,40 \\
\hline 9 Playa F. & 76 & 99,6 & 99,4 & 99,2 & 90,8 & 70,3 & 18,7 & 1,14 \\
\hline 10 Playa & 96 & 99,1 & 94,8 & 80,7 & 57,7 & 15,2 & 3,8 & 2,49 \\
\hline 11 Machađ. & 61 & 100 & 99,2 & 75,3 & 55,5 & 34,6 & 25,0 & 2,10 \\
\hline 12 Machad. & 66 & 100 & 99,4 & 83,7 & 62,5 & 40,3 & 30,5 & 1,84 \\
\hline
\end{tabular}

Forma de los granos: Sin modificación.

Tamaño máximo del grano: El actual límite de $5 \mathrm{~mm}$ se juzga alto en la mayoría de los casos. Se propone el limite de $2,5 \mathrm{~mm}$ como conveniente para todos ellos, exigiendo que el $90 \%$ en peso de la arena pase por dicho tamiz. Aunque esta exigencia no la han cumplido todas las arenas ensayadas, la buena práctica del cribado consigue con poco coste su cumplimiento. 


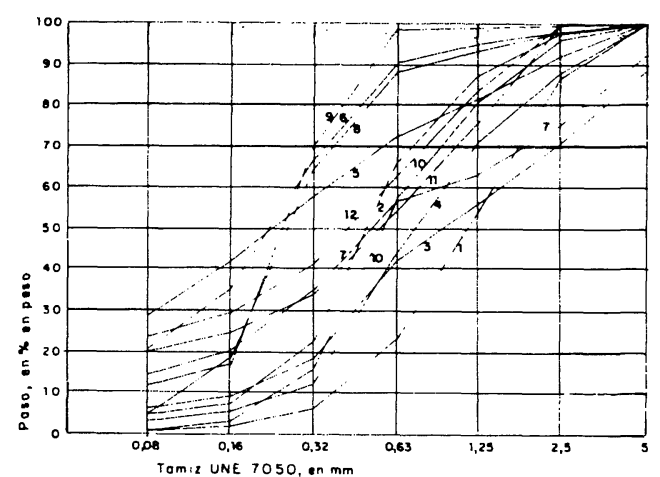

Fig. 1.-Granulometria de las arenas suministradas.

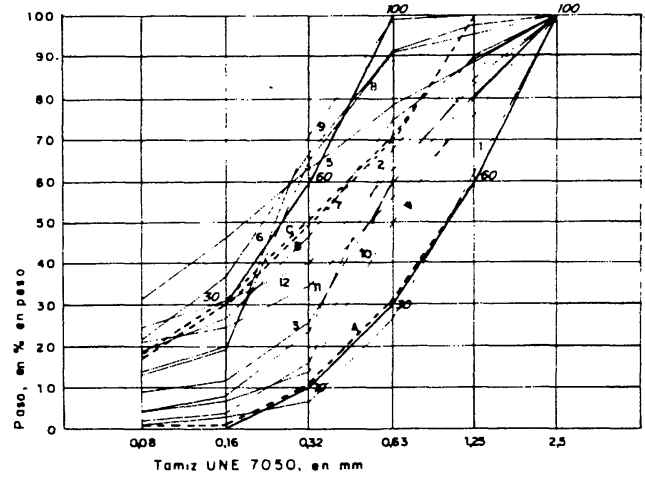

Fig. 2.-Granulometría de la fracción $<2,5 \mathrm{~mm}$ de las arenas suministradas, de las arenas compuestas A, B, C, y limites propuestos.

C UADRO 6

Cumplimiento de las condiciones por las arenas

\begin{tabular}{|c|c|c|}
\hline Condición & Exigencia & $\begin{array}{l}\text { Io cumplen, } \\
\text { en } 8\end{array}$ \\
\hline Forma de los granos & Rédonda o joliédrica & 100 \\
\hline Tamario maxirio: & $\left\{\begin{array}{lll}\text { Toda } & \leq 5 & \mathrm{~mm} \\
90 & \leq 5 & \mathrm{~mm} \\
90 & \div 2,5 & \mathrm{~mm}\end{array}\right.$ & $\begin{array}{l}17 \\
92 \\
67\end{array}$ \\
\hline Contenido de finos: & $\leq 15 \stackrel{\circ}{c}$ & 67 \\
\hline Granulometría: & 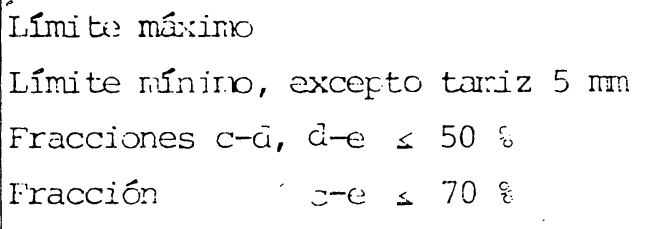 & $\begin{array}{l}42 \\
100 \\
100 \\
100\end{array}$ \\
\hline Conterida de materia organica: & Fdrisible & 92 \\
\hline Contenido de compuestos de azufre: & $=1,28$ & 100 \\
\hline Otras impurezas: & Ensayo en general no viabie & - \\
\hline $\begin{array}{l}\text { Reactividad potencial con los } \\
\text { álcalis del oemento: }\end{array}$ & Negativa & 1.00 \\
\hline
\end{tabular}

Contenido de finos: El mortero fresco necesita tener un minimo contenido de finos, suma del de la arena, y el del cemento, y en su caso la cal, para conseguir una plasticidad adecuada a su colocación con la paleta. Una arena con un bajo contenido de finos exige alta dosificación de conglomerante, lo que encarece el mortero. Un alto contenido de finos cuando son de arcilla es muy perjudicial por la reducción de resistencia y el aumento de heladicidad que se produce (9), (17), (18), (19), (20), pero cuando son de polvo de piedra machacada, o limo, solamente aumenta la relación agua: cemento. Su influencia (21) es moderada, y se propone que no se requiera cumplir la exigencia del máximo único del $5 \%$ de finos en arenas para hormigones, cuando la suma del porcentaje de finos y del equivalente de arena no sea superior a $70 \%$. 
A la vista de los resultados obtenidos en los ensayos de resistencia de morteros, se propone adoptar este criterio.

Granulometría: La granulometria debe realizarse sobre la fracción que pase por el tamiz 2,5 UNE 7050, separando la parte mayor, que según se expresó al definir el tamaño máximo, no será superior al $10 \%$.

Los resultados de los ensayos efectuados en las arenas y las resistencias de morteros obtenidos, que se analizan luego, permiten simplificar las condiciones exigibles para la granulometria, que se reflejan en la propuesta.

Contenido de materia orgánica: Sin modificación.

Contenido de impurezas: Las sustancias de la arena que pueden ser verdaderamente perjudiciales para el cemento del mortero son los compuestos de azufre, y su determinación es sencilla y precisa. Por eso ha parecido conveniente sustituir la condición actual de contenido de impurezas por un limite de $1,2 \%$ en el contenido de compuestos de azufre, expresados en $\mathrm{SO}_{4}^{--}$, como se exigen en las arenas empleadas en la confección de hormigones en masa o armados (22), o pretensados (23), y que está perfectamente sancionado por la práctica, habiéndose producido desperfectos, a veces graves, en cuanto se rebasa.

Reactividad potencial con los álcalis del cemento: La condición de reactividad potencial negativa, que se exige a las arenas para hormigones (22), (23), no figura en la Norma MV 201 1972, pero parece conveniente incluirla, aun cuando sean raros los casos en que no se cumple, arenas de machaqueo de ciertos granitos, y otras. Las doce arenas ensayadas la han cumplido.

\subsection{Arenas compuestas}

Además de las doce arenas descritas en 2.4 se prepararon tres arenas compuestas obtenidas mezclando fracciones $2,5-1,25 ; 1,25-0,63 ; 0,63-0,32 ; 0,32-0,16$ y $0,16-0,08$ separadas por cribado en seco de la arena caliza de machaqueo, procedente de Tiebas (Navarra), y, según los casos, polvo de caliza $<0,08$, o una arcilla de modelar fina y sin granos superiores a 0,08 .

El criterio para preparar estas arenas fue el siguiente:

Arena A: Módulo granulométrico máximo posible: 3,00, según las limitaciones de la Propuesta de revisión. Se obtuvo mezclando las siguientes cantidades:

\begin{tabular}{lccccc} 
Fracción & $2,5-1,25$ & $1,25-0,63$ & $0,63-0,32$ & $0,32-0,16$ & $0,16-0,08$ \\
\hline$\%$ en peso & 40 & 30 & 20 & 10 & 0
\end{tabular}

Al haber efectuado en seco el cribado de la arena quedaron finos adheridos en la superficie de los granos. El contenido de finos en el ensayo de levigación fue de $2,1 \%$ y su equivalente de arena de $93 \%$.

Arena B: Módulo granulométrico mitad del máximo: 1,50. Linea granulométrica entre los límites propuestos. Contenido de finos de polvo de caliza: $15 \%$, igual al máximo permitido en la actual MV 201-1972. Se obtuvo mezclando las siguientes cantidades:

\begin{tabular}{lcccccc} 
Fracción & $2,5-1,25$ & $1,25-0,63$ & $0,63-0,32$ & $0,32-0,16$ & $0,16-0,08$ & $<0,08$ \\
\hline$\%$ en peso & 0 & 30 & 20 & 20 & 15 & 15
\end{tabular}

Por la razón anterior los finos en levigación fueron: $18 \%$ y el equivalente de arena $68 \%$. 
Arena $C$ : Igual a la $\mathrm{B}$, pero con finos de arcilla. En levigación se obtuvo: 19,4\%, y cl equivalente de arena $45 \%$.

Las líneas granulométricas de las arenas A, B, C, y los límites que figuran en la Propuesta del Capitulo 3, se representan en la figura 2.

\subsection{Aguas}

Las condiciones exigidas en la Norma MV 201-1972 al agua que se emplea en el amasado del mortero y en el humedecimiento de los ladrillos, coinciden casi a la letra con las que se exigen para los hormigones (22), (23). No se conoce ningún caso en que cumpliendo estas condiciones se hayan producido defectos, y por ello no se ha realizado experimentación con aguas.

En la confección de los morteros se ha empleado el agua potable suministrada por el Servicio Municipal de Aguas de Pamplona, que es la utilizada en todas las obras de la ciudad.

\subsection{Aditivos}

Actualmente en la confección de morteros para fábricas de ladrillo se emplean a veces aditivos plastificantes, (20), (24), (25), (26) con objeto de mejorar la plasticidad del mortero.

En este estudio se han confeccionado algunos morteros de plasticidad deficiente con aditivo plastificante, con objeto de tener datos sobre su influencia, sin proceder a una investigación a fondo de esta cuestión que no era objeto de este trabajo.

El aditivo empleado fue SIKANOL-M, cuya composición, como ocurre en la mayoria de los aditivos comercializados, es desconocida, y se siguieron las indicaciones de dosificación recomendada por la casa SIKA fabricante de dicho producto.

Al producto líquido se agregó el agua de amasado en proporción de $0,2 \%$ del peso del cemento más el de la cal en su caso, que se indica para morteros amasados a mano.

El Grupo de Trabajo propuso una modificación del correspondiente artículo de la Norma haciendo referencia explícita al Documento de Idoneidad Técnica (27) o a la experimentación realizada, exigiendo su inclusión en las Prescripciones Técnicas Particulares del Proyecto, o la autorización del Director de Obra.

\section{CAPITULO 3. ESTUDIO DE LOS MORTEROS}

\subsection{Generalidades}

El principal objeto de este estudio ha sido determinar la resistencia que se obtiene con morteros confeccionados con cemento PA-350, que es el de uso más frecuente en la actualidad, con objeto de establecer una Tabla equivalente a la Tabla 3.5 de la Norma MV 201-1972, en la que figura como fundamental el cemento P-250, que era el usual antes de aparecer el Pliego RC-75, y que ha dejado de fabricarse.

Otras propiedades de los morteros han sido estudiadas según las tendencias actuales (9), (10), (28), (29), (30), (31), (32), y se han realizado ensayos, especialmente para determinar la influencia de la clase y contenido de finos de la arena, determinados mediante el ensayo de levigación y el del equivalente de arena, lo que ha permitido hacer una propuesta sobre la cuestion. 
Las determinaciones efectuadas sobre los componentes del mortero, sobre el mortero fresco y sobre el mortero endurecido, han suministrado datos sobre la influencia de las caracteristicas de los materiales, y de su dosificación, en las propiedades del mortero fresco y endurecido, como se detalla a continuación.

\subsection{Dosificación de los morteros fabricados}

De acuerdo con el epigrafe "3.2.2." de la propuesta, la dosificación de los componentes: cemento, en su caso cal, y arena, de los morteros para ensayo se estableció en peso.

La serie I, se compone de morteros con relación cemento : arena, de valores $1: 3,1: 6$ y $1: 10$, confeccionados con las 12 arenas enviadas (2.5), obteniéndose en total 36 tipos diferentes de mortero. Las dosificaciones elegidas corresponden a contenidos de cemento máximo, medio y mínimo que se juzgan posibles para morteros de fábrica.

CUADRO 7

Dosificaciones de los morteros de la serie II

\begin{tabular}{|c|c|c|c|c|c|}
\hline \multirow[b]{2}{*}{ Arena } & \multicolumn{3}{|c|}{ Dosificacion en peso } & \multirow[b]{2}{*}{ Aditivo } & \multirow[b]{2}{*}{ Objeto } \\
\hline & Cemento & $\mathrm{Cal}$ & Arena & & \\
\hline \multirow[t]{14}{*}{ A } & 1 & 0 & 3 & No & \multirow{3}{*}{$\begin{array}{l}\text { Comparar con los } \\
\text { morteros de la } \\
\text { Serie I }\end{array}$} \\
\hline & 1 & 0 & 6 & No & \\
\hline & 1 & 0 & 10 & No & \\
\hline & 1 & 0,5 & 4,5 & No & \multirow{5}{*}{$\begin{array}{l}\text { Investigar la in- } \\
\text { fluencia de la adi } \\
\text { ción de cal. }\end{array}$} \\
\hline & 1 & 1 & 6 & No & \\
\hline & 1 & 1,5 & 7,5 & No & \\
\hline & 1 & 2 & 9 & No & \\
\hline & 1 & 3 & 12 & No & \\
\hline & 1 & 0 & 4 & $\mathrm{Si}$ & \multirow{6}{*}{$\begin{array}{l}\text { Obtener datos de } \\
\text { morteros con adi- } \\
\text { tivos plastifican } \\
\text { tes sin y con cal }\end{array}$} \\
\hline & 1 & 0,5 & 6 & Si & \\
\hline & 1 & 1 & 8 & $\mathrm{Si}$ & \\
\hline & 1 & 0 & 5 & Si & \\
\hline & 1 & 0,5 & 7,5 & $\mathrm{Si}$ & \\
\hline & 1 & 1 & 10 & $\mathrm{Si}$ & \\
\hline \multirow[t]{6}{*}{$B$ y C } & 1 & 0 & 6 & SiONO & \multirow{6}{*}{$\begin{array}{l}\text { Investigar la in- } \\
\text { fluencia de la na } \\
\text { turaleza de los } \\
\text { finos en la resis } \\
\text { tencia. }\end{array}$} \\
\hline & 1 & 0,5 & 9 & SiONo & \\
\hline & 1 & 1 & 12 & Si O NO & \\
\hline & 1 & 0 & 9 & $\mathrm{Si}$ & \\
\hline & 1 & 0,5 & 13,5 & Si & \\
\hline & 1 & 1 & 18 & $\mathrm{Si}$ & \\
\hline $\begin{array}{l}1,4 \quad y \\
10\end{array}$ & 1 & 2,33 & 10 & Si & $\begin{array}{l}\text { Comparar con los } \\
\text { morteros de la se } \\
\text { rie I, empleando } \\
\text { dosificación alta } \\
\text { de cal. }\end{array}$ \\
\hline
\end{tabular}


La serie II se compone de 29 tipos de mortero, con las dosificaciones en peso que se establecen en el Cuadro 7.

\subsection{Confección de los morteros de ensayo}

Se fabricó un volumen de 7-8 litros de mortero fresco con cada una de las dosificaciones establecidas. El cemento, la cal aérea apagada en polvo en su caso, y la arena, se pesaron en balanza, con precisión de $0,01 \mathrm{~kg}$. Se vertieron sobre una carretilla de chapa, limpia y seca y se mezclaron a mano con paleta, por un operario con reconocida experiencia de albañil, hasta obtener una mezcla uniforme a la vista, en un lapso no inferior a 1 minuto.

Sobre la mezcla seca se fue agregando agua, medida con probetas graduadas de precisión $0,01 \mathrm{l}$, y se amasó a mano con paleta, hasta obtener una mezcla uniforme a la vista, en lapso no inferior a 1 minuto. Cuando la docilidad de la masa, a juicio del operario, fue la conveniente, se midió la consistencia con cono Abrams, aceptándose la masa si el asiento era de $17 \pm 2 \mathrm{~cm}$, valor indicado en la Norma MV 201-1972. Cuando el asiento fue menor se añadió agua, igualmente medida, hasta intentar conseguir dicho valor.

En la Serie I de morteros sin cal, con arenas de bajo contenido de finos, y en las de playa, no fue posible llegar a este asiento, ya que se produce segregación con asientos menores. Este fenómeno se acentuó con morteros de bajo contenido de cemento. En los morteros con cal de la Serie II ocurrió obtener asientos algo mayores, $20-22 \mathrm{~cm}$, con masas de docilidad apropiada a juicio del operario, variando mucho la consistencia de estos morteros con pequeños aumentos de agua.

Con la masa definitiva se midió además la consistencia mediante el asiento en el denominado cono 15, construido especialmente para este estudio, con dimensiones mitad del cono Abrams. También se midió mediante el ensayo con mesa de sacudidas según el método de la Norma UNE 7205 .

Los resultados de los ensayos de los morteros figuran en el Anejo 3 de este Estudio y se presentan sistematizados en el cuadro 8 los de los 36 morteros de la Serie I, y en el cuadro 9 los de los 29 morteros de la Serie II.

La comparación entre los asientos en cono Abrams y en cono 15 se presenta en la figura 3. La comparación entre los asientos en cono Abrams, y los escurrimientos con la mesa de sacudidas, se presentan en la figura 4.

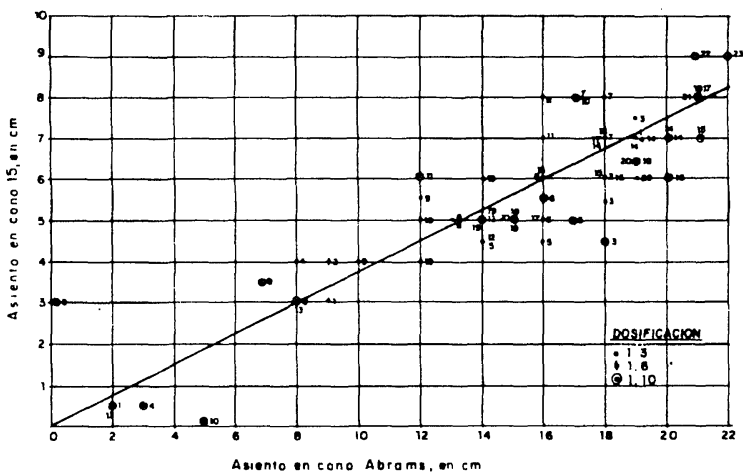

Fig. 3.-Comparación de los ensayos con cono Abrams y cono 15 .

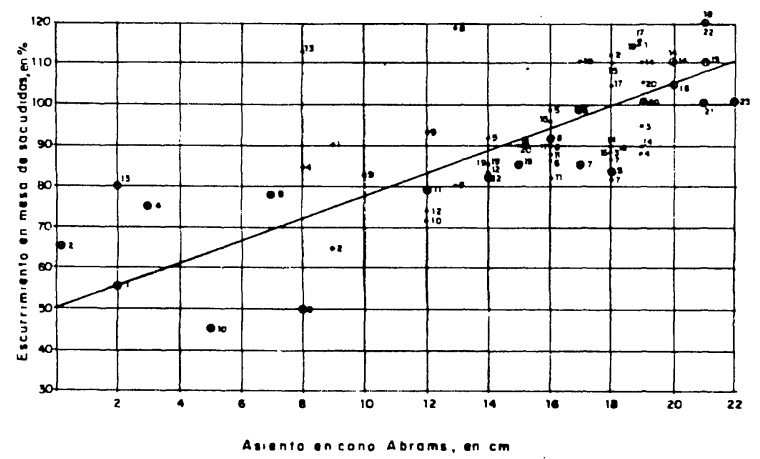

Fig. 4.- Comparación de los ensayos con cono Abrams y mesa de sacudidas. 
CUADRO 8

De los ensayos sobre los morteros de la Serie I

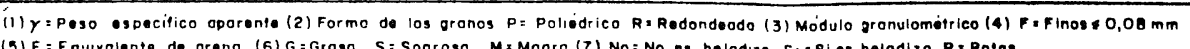

\begin{tabular}{|c|c|c|c|c|c|c|c|c|c|c|c|c|c|c|c|c|c|c|c|c|c|c|c|c|c|c|c|c|c|c|c|c|c|}
\hline \multirow{3}{*}{\multicolumn{3}{|c|}{ 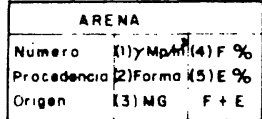 }} & \multicolumn{12}{|c|}{ MORTE RO } & \multicolumn{6}{|c|}{ MORTERO ENOURECIOO A 28 DIAS } & \multicolumn{13}{|c|}{ RESISTENCIAS MECA } \\
\hline & & & \multicolumn{7}{|c|}{ 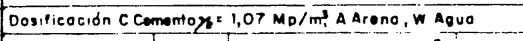 } & \multirow{2}{*}{\multicolumn{3}{|c|}{$\begin{array}{l}\text { Consistencio } \\
\text { Cono A Cono } 15 \text { Maso }\end{array}$}} & \multicolumn{2}{|c|}{ Planticlidod } & \multirow{2}{*}{$\begin{array}{l}\text { poso } \\
\text { ospocif } \\
\mathrm{Mp}_{\mathrm{p}} / \mathrm{m}^{\mathrm{s}}\end{array}$} & \multirow{2}{*}{$\begin{array}{l}\text { Humedoco } \\
\%\end{array}$} & \multirow[t]{2}{*}{ Aabsorctió } & \multirow{2}{*}{$\begin{array}{l}\text { Perdid } \\
\quad \% \\
\end{array}$} & \multirow{2}{*}{\multicolumn{2}{|c|}{\begin{tabular}{|l} 
Colli \\
171
\end{tabular}}} & \multicolumn{5}{|c|}{ 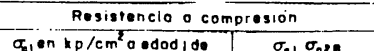 } & \multicolumn{5}{|c|}{ Ressisionclo o flosotracción } & \multirow{2}{*}{\multicolumn{3}{|c|}{ Relacion $\sigma_{1 f}: \sigma_{01}$}} \\
\hline & & & CA & $\begin{array}{cc}C & A \\
\text { nnvommen } & \end{array}$ & 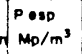 & $\frac{k p d e c o}{c}$ & $\prod_{A}^{m p o n e n t e ~}$ & por $m^{2}$ & wc & $\begin{array}{cl}\operatorname{cono} A \\
c m\end{array}$ & & $\begin{array}{c}\text { Maso } \\
\%\end{array}$ & $\begin{array}{l}\text { (4) } F \\
\%\end{array}$ & (6) & & & & & & & $\frac{a_{0}, \operatorname{en} \times p}{7 d}$ & 280 & $\frac{00100}{910}$ & $\frac{\sigma_{01}}{70}$ & $\frac{0.20}{919}$ & $\frac{g_{0}, \operatorname{nop} p /}{70}$ & $\frac{2 c^{2} 0000}{28 d}$ & $\frac{d 1 d e}{91 d}$ & $\frac{\sigma_{i i}}{70}$ & $\frac{\sigma_{\text {and }}}{1910}$ & & & \\
\hline $\begin{array}{l}\text { Barcolono } \\
\text { Rio }^{2}\end{array}$ & $\begin{array}{l}1,47 \\
p \\
3,29\end{array}$ & $\begin{array}{l}1,2 \\
97 \\
90\end{array}$ & $\begin{array}{l}1: 3 \\
116 \\
110\end{array}$ & $\begin{array}{l}1,2,18 \\
1,4,38 \\
1: 7,28\end{array}$ & $\begin{array}{l}2.193 \\
2.133 \\
1,845\end{array}$ & $\begin{array}{l}470 \\
258 \\
142\end{array}$ & $\begin{array}{l}1410 \\
1546 \\
1419\end{array}$ & $\begin{array}{l}313 \\
329 \\
284\end{array}$ & $\begin{array}{l}0,68 \\
1,28 \\
2,00\end{array}$ & $\begin{array}{r}19 \\
9 \\
2\end{array}$ & $\begin{array}{l}7 \\
3 \\
0,5\end{array}$ & $\begin{array}{l}115 \\
90 \\
35\end{array}$ & $\begin{array}{r}24 \\
14 \\
9\end{array}$ & $\begin{array}{l}\mathrm{S} \\
M \\
M\end{array}$ & $\begin{array}{l}2,12 \\
2,01 \\
1,79\end{array}$ & $\begin{array}{l}6,0 \\
4,6 \\
2,8\end{array}$ & $\begin{array}{l}11,5 \\
11,7 \\
11,2\end{array}$ & $\begin{array}{l}0 \\
2 \\
R\end{array}$ & & $\begin{array}{l}\text { No } \\
\text { No } \\
\text { Si }\end{array}$ & $\begin{array}{r}158 \\
39 \\
B\end{array}$ & $\begin{array}{r}231 \\
13 \\
22\end{array}$ & $\begin{array}{r}275 \\
78 \\
23\end{array}$ & $\begin{array}{l}0,68 \\
0,53 \\
0,27\end{array}$ & $\begin{array}{l}1,19 \\
1,07 \\
1,05\end{array}$ & $\begin{array}{l}43 \\
14\end{array}$ & $\begin{array}{l}49 \\
19 \\
8\end{array}$ & $\begin{array}{r}53 \\
20 \\
9\end{array}$ & $\begin{array}{l}0,88 \\
0,74 \\
0,13\end{array}$ & $\begin{array}{l}1,12 \\
1,05 \\
1,13\end{array}$ & $\begin{array}{l}0,27 \\
0,36 \\
0,17\end{array}$ & $\begin{array}{l}0,21 \\
0,28 \\
0,38\end{array}$ & $\begin{array}{l}0,26 \\
0,26 \\
0,39\end{array}$ \\
\hline rono & $\begin{array}{l}1,48 \\
p \\
3,16\end{array}$ & $\begin{array}{l}4,6 \\
89 \\
94\end{array}$ & $\begin{array}{l}1.3 \\
1.8 \\
110\end{array}$ & $\left\{\begin{array}{l}12,17 \\
1,34 \\
17,23\end{array}\right.$ & $\begin{array}{l}2,164 \\
2,007 \\
2,020\end{array}$ & $\begin{array}{l}480 \\
242 \\
153\end{array}$ & $\begin{array}{l}1381 \\
1455 \\
1530\end{array}$ & $\begin{array}{l}323 \\
310 \\
337\end{array}$ & $\begin{array}{l}0,70 \\
1,28 \\
2,20\end{array}$ & $\begin{array}{l}18 \\
9 \\
-\end{array}$ & : & $\begin{array}{l}113 \\
63 \\
65\end{array}$ & $\begin{array}{l}26 \\
17 \\
13\end{array}$ & $\begin{array}{l}G \\
S \\
M\end{array}$ & $\begin{array}{l}2,08 \\
1,88 \\
1,91\end{array}$ & $\begin{array}{l}6,5 \\
4,5 \\
3,3\end{array}$ & $\begin{array}{l}11,7 \\
12,1 \\
12,0\end{array}$ & $\begin{array}{c}0 \\
2 \\
18\end{array}$ & & $\begin{array}{l}\text { No } \\
\text { No } \\
\text { St }\end{array}$ & $\begin{array}{r}167 \\
39 \\
9\end{array}$ & $\begin{array}{r}255 \\
73 \\
19\end{array}$ & $\begin{array}{r}277 \\
80 \\
21\end{array}$ & $\begin{array}{l}0,65 \\
0,53 \\
0,47\end{array}$ & $\begin{array}{l}1,09 \\
1,18 \\
1,11\end{array}$ & $\begin{array}{l}41 \\
17 \\
3\end{array}$ & $\begin{array}{r}33 \\
20 \\
3\end{array}$ & $\begin{array}{r}03 \\
23 \\
7\end{array}$ & $\begin{array}{l}0,77 \\
0,03 \\
0,80\end{array}$ & $\begin{array}{l}1,19 \\
1,15 \\
1,40\end{array}$ & $\begin{array}{l}0,29 \\
0,44 \\
0,33\end{array}$ & $\begin{array}{l}0,21 \\
0,27 \\
0,28\end{array}$ & $\begin{array}{l}0,23 \\
0,27 \\
0,33\end{array}$ \\
\hline & $\begin{array}{l}1,85 \\
p \\
3,13\end{array}$ & \begin{tabular}{|l}
6,5 \\
07 \\
94
\end{tabular} & $\begin{array}{c}13 \\
13 \\
110\end{array}$ & $\begin{array}{r}1,95 \\
1,90 \\
1,9,48 \\
16, \\
\end{array}$ & $\mid \begin{array}{l}2295 \\
2,216 \\
2,214\end{array}$ & $\begin{array}{l}503 \\
275 \\
175\end{array}$ & $\begin{array}{l}1508 \\
1850 \\
1748\end{array}$ & $\begin{array}{l}284 \\
291 \\
291\end{array}$ & $\begin{array}{l}0,57 \\
1,06 \\
1,86\end{array}$ & $\begin{array}{l}19 \\
10 \\
10\end{array}$ & $\begin{array}{l}7,5 \\
2,5 \\
4,5\end{array}$ & $\begin{array}{l}95 \\
87 \\
82\end{array}$ & $\begin{array}{l}28 \\
19 \\
14 \\
\end{array}$ & $\begin{array}{l}B \\
3 \\
M\end{array}$ & $\begin{array}{l}2,25 \\
2,11 \\
2,10\end{array}$ & $\begin{array}{l}6,1 \\
4,2 \\
2,3\end{array}$ & $\begin{array}{r}9,5 \\
10,3 \\
9,5\end{array}$ & $\begin{array}{l}0 \\
1 \\
17\end{array}$ & & $\begin{array}{l}\text { No } \\
\text { No } \\
\text { SI }\end{array}$ & $\begin{array}{r}294 \\
83 \\
27\end{array}$ & $\begin{array}{r}353 \\
116 \\
56\end{array}$ & $\begin{array}{c}308 \\
134 \\
84\end{array}$ & $\begin{array}{l}0,83 \\
0,72 \\
0,48\end{array}$ & $\begin{array}{l}1,10 \\
116 \\
1,14\end{array}$ & $\begin{array}{l}35 \\
25 \\
10\end{array}$ & $\begin{array}{l}84 \\
31 \\
13\end{array}$ & $\begin{array}{l}81 \\
32 \\
16\end{array}$ & $\begin{array}{l}0,86 \\
0,81 \\
0,77\end{array}$ & $\begin{array}{l}1,27 \\
1,03 \\
1,23\end{array}$ & $\begin{array}{l}0,19 \\
0,30 \\
0,37\end{array}$ & $\begin{array}{l}0,18 \\
0,27 \\
0,23\end{array}$ & $\begin{array}{l}0,21 \\
0,24 \\
0,29\end{array}$ \\
\hline dr & $\begin{array}{l}1,40 \\
p \\
2,79\end{array}$ & $\begin{array}{l}4,5 \\
90 \\
95\end{array}$ & $\begin{array}{l}13 \\
16 \\
110\end{array}$ & $\begin{array}{l}12,17 \\
14,34 \\
1,7,23\end{array}$ & \begin{tabular}{|l}
2,248 \\
2,113 \\
1,993
\end{tabular} & $\begin{array}{l}478 \\
254 \\
152\end{array}$ & & $\begin{array}{l}335 \\
338 \\
318\end{array}$ & $\begin{array}{l}0,70 \\
1,33 \\
2,08\end{array}$ & $\begin{array}{r}19 \\
3 \\
3\end{array}$ & $\begin{array}{l}7 \\
0,5\end{array}$ & $\begin{array}{l}87 \\
85 \\
75\end{array}$ & $\begin{array}{l}26 \\
17 \\
13\end{array}$ & $\begin{array}{l}0 \\
\text { M } \\
\text { M }\end{array}$ & & $\begin{array}{l}6,2 \\
4,0 \\
2,5\end{array}$ & $\begin{array}{l}10,5 \\
11,9 \\
12,9\end{array}$ & $\begin{array}{l}0 \\
24 \\
n\end{array}$ & & $\begin{array}{l}\text { No } \\
\text { Si } \\
\text { Si }\end{array}$ & $\begin{array}{l}168 \\
39 \\
12\end{array}$ & $\begin{array}{r}278 \\
81 \\
19\end{array}$ & $\begin{array}{r}305 \\
72 \\
21\end{array}$ & & $\begin{array}{l}1,10 \\
1,18 \\
1,11\end{array}$ & & 97 & $\begin{array}{r}59 \\
18 \\
7\end{array}$ & & $\begin{array}{l}1,04 \\
1,20 \\
1,17\end{array}$ & & & $\begin{array}{l}0.19 \\
0,25 \\
0,33\end{array}$ \\
\hline $\begin{array}{l}\text { Aliconte } \\
\text { canterse }\end{array}$ & $\begin{array}{l}1,30 \\
p \\
1,33\end{array}$ & $\begin{array}{l}22,3 \\
28 \\
57\end{array}$ & $\begin{array}{l}13 \\
18 \\
110\end{array}$ & $\begin{array}{l}12,31 \\
14,82 \\
1,70\end{array}$ & $\begin{array}{l}2,037 \\
2,009 \\
1,977\end{array}$ & $\begin{array}{l}414 \\
233 \\
148\end{array}$ & $\begin{array}{l}1243 \\
1400 \\
1435\end{array}$ & $\begin{array}{l}380 \\
378 \\
378\end{array}$ & $\begin{array}{l}0,92 \\
1,81 \\
2,80\end{array}$ & $\begin{array}{l}14 \\
18 \\
17\end{array}$ & $\begin{array}{l}4,5 \\
4,5 \\
5\end{array}$ & $\begin{array}{l}92 \\
98 \\
98\end{array}$ & $\begin{array}{l}45 \\
38 \\
35\end{array}$ & $\begin{array}{l}6 \\
6 \\
G\end{array}$ & & $\begin{array}{l}8,2 \\
9,6 \\
3,7\end{array}$ & $\begin{array}{l}17,2 \\
18,1 \\
18,6\end{array}$ & $\begin{array}{l}29 \\
52 \\
R\end{array}$ & & $\begin{array}{l}\text { si } \\
\text { s1 } \\
\text { si }\end{array}$ & $\begin{array}{r}136 \\
31 \\
6\end{array}$ & $\begin{array}{r}148 \\
55 \\
13\end{array}$ & $\begin{array}{c}197 \\
81 \\
18\end{array}$ & $\begin{array}{l}0,92 \\
0,96 \\
0,46\end{array}$ & $\begin{array}{l}1,33 \\
1,11 \\
1,23\end{array}$ & $\begin{array}{l}32 \\
12 \\
1\end{array}$ & $\begin{array}{r}44 \\
13 \\
2\end{array}$ & $\begin{array}{r}45 \\
13 \\
3\end{array}$ & & & & $\begin{array}{l}0,30 \\
0,24 \\
0,15\end{array}$ & $\begin{array}{l}0,23 \\
0,21 \\
0,19\end{array}$ \\
\hline $\begin{array}{l}\text { doso (Na) } \\
\text { intero }\end{array}$ & $\begin{array}{l}1,45 \\
R \\
1,13\end{array}$ & $\begin{array}{l}21,2 \\
29 \\
50\end{array}$ & $\begin{array}{l}13 \\
18 \\
110\end{array}$ & $\begin{array}{l}12,21 \\
14,42 \\
17,38\end{array}$ & $\begin{array}{l}2,098 \\
2,041 \\
2,044\end{array}$ & $\begin{array}{l}429 \\
235 \\
130\end{array}$ & & $\begin{array}{l}398 \\
393 \\
398\end{array}$ & $\begin{array}{l}0,93 \\
1,66 \\
2,68\end{array}$ & $\begin{array}{l}16 \\
16 \\
16\end{array}$ & $\begin{array}{l}6 \\
5 \\
5,5\end{array}$ & $\begin{array}{l}85 \\
90 \\
91\end{array}$ & $\begin{array}{l}38 \\
31 \\
28\end{array}$ & $\begin{array}{l}0 \\
0 \\
0\end{array}$ & & $\begin{array}{l}7,2 \\
4,2 \\
2,8\end{array}$ & $\begin{array}{r}18,9 \\
! 18,3 \\
19,3\end{array}$ & $\begin{array}{l}3 \\
47 \\
8\end{array}$ & & $\begin{array}{l}\text { No } \\
\text { S1 } \\
\text { S1 }\end{array}$ & $\begin{array}{r}123 \\
25 \\
-\quad 8\end{array}$ & $\begin{array}{r}142 \\
36 \\
14\end{array}$ & $\begin{array}{r}172 \\
42 \\
14\end{array}$ & $\begin{array}{l}0,87 \\
0,69 \\
0,43\end{array}$ & $\begin{array}{l}1,17 \\
1,00\end{array}$ & 1 & $\begin{array}{r}45 \\
13 \\
3\end{array}$ & $\begin{array}{c}45 \\
14 \\
3\end{array}$ & & & & $\begin{array}{l}32 \\
38 \\
21\end{array}$ & $\begin{array}{l}0,28 \\
0,33 \\
0,21\end{array}$ \\
\hline $\begin{array}{l}\text { Pudela (No) } \\
\text { Eantero }\end{array}$ & $\begin{array}{c}1,62 \\
p \\
2,55\end{array}$ & $\begin{array}{l}14,0 \\
62 \\
70\end{array}$ & $\begin{array}{l}13 \\
18 \\
110\end{array}$ & $\begin{array}{l}1,98 \\
1,98 \\
1,96 \\
16,60\end{array}$ & $\begin{array}{l}2,254 \\
2,258 \\
2,207\end{array}$ & $\begin{array}{l}483 \\
278 \\
174\end{array}$ & $\begin{array}{l}1449 \\
1670 \\
1742\end{array}$ & $\begin{array}{l}322 \\
310 \\
291\end{array}$ & & $\begin{array}{l}18 \\
18 \\
17\end{array}$ & $\begin{array}{l}7 \\
8 \\
8\end{array}$ & $\begin{array}{l}82 \\
88 \\
\text { A5 }\end{array}$ & $\begin{array}{l}33 \\
25 \\
21\end{array}$ & $\begin{array}{l}G \\
G \\
S\end{array}$ & & $\begin{array}{r}7,1 \\
4,8 \\
3,0 \\
-\quad .\end{array}$ & $\begin{array}{l}11,6 \\
11,1 \\
-11,3\end{array}$ & ' & & $\begin{array}{l}\text { No } \\
\text { No } \\
\text { SI }\end{array}$ & $\begin{array}{r}248 \\
89 \\
27\end{array}$ & $\begin{array}{r}333 \\
123 \\
47\end{array}$ & $\begin{array}{r}388 \\
158 \\
55\end{array}$ & $\begin{array}{l}0,74 \\
0,72 \\
0,57\end{array}$ & $\begin{array}{l}1,17 \\
1,28 \\
1,17\end{array}$ & & & $\begin{array}{l}84 \\
38 \\
13\end{array}$ & & $\begin{array}{l}.08 \\
19 \\
15\end{array}$ & & & $\begin{array}{l}916 \\
0,24 \\
9227\end{array}$ \\
\hline obostion & $\begin{array}{l}1,21 \\
1,40\end{array}$ & $\begin{array}{l}5,4 \\
90 \\
95\end{array}$ & $\begin{array}{l}13 \\
118 \\
110\end{array}$ & $\begin{array}{r}12,65 \\
1 \\
1,30 \\
18,84\end{array}$ & $\begin{array}{r}1,989 \\
1,901 \\
1,773\end{array}$ & $\begin{array}{l}390 \\
202 \\
120\end{array}$ & & & & $\begin{array}{r}13 \\
13 \\
8\end{array}$ & $\begin{array}{r}5 \\
3 \\
3 \\
-\end{array}$ & $\begin{array}{r}80 \\
118 \\
50\end{array}$ & $\begin{array}{l}27 \\
18 \\
13\end{array}$ & $\begin{array}{l}G \\
S \\
M\end{array}$ & & $\begin{array}{l}9,2 \\
6,3 \\
3,6\end{array}$ & $\begin{array}{r}18,8 \\
21.9 \\
24,8\end{array}$ & $\begin{array}{l}\text { i } \\
\text { R }\end{array}$ & & $\begin{array}{l}\text { s1 } \\
\text { s1 } \\
\text { s1 }\end{array}$ & $\begin{array}{r}102 \\
13 \\
0\end{array}$ & $\begin{array}{r}117 \\
22 \\
3\end{array}$ & $\begin{array}{r}170 \\
120 \\
6\end{array}$ & $\begin{array}{l}0,87 \\
0,59 \\
0\end{array}$ & $\begin{array}{l}1,45 \\
3,45 \\
2\end{array}$ & $\begin{array}{l}5 \\
0\end{array}$ & $i$ & $\begin{array}{r}35 \\
2\end{array}$ & $\begin{array}{l}0,79 \\
0,56 \\
0\end{array}$ & \begin{tabular}{|l|}
1,21 \\
3,09 \\
2,00
\end{tabular} & $\begin{array}{l}0,29 \\
0,38 \\
-\end{array}$ & $\begin{array}{l}0,32 \\
0,41 \\
0,33\end{array}$ & $\begin{array}{l}0,27 \\
0,29 \\
0,33\end{array}$ \\
\hline lavilla & $\begin{array}{l}1,31 \\
R \\
1,14\end{array}$ & $\begin{array}{l}12,7 \\
78 \\
18\end{array}$ & $\begin{array}{l}13 \\
18 \\
110\end{array}$ & $\begin{array}{l}12,45 \\
14,90 \\
18,17\end{array}$ & $\begin{array}{l}2,110 \\
2,007 \\
1,934\end{array}$ & $\begin{array}{l}428 \\
227 \\
139\end{array}$ & & $\begin{array}{l}399 \\
417 \\
405\end{array}$ & & $\begin{array}{r}10 \\
7\end{array}$ & $\begin{array}{l}3,5 \\
4,5\end{array}$ & $\begin{array}{l}94 \\
84 \\
77\end{array}$ & $\begin{array}{l}32 \\
24 \\
20\end{array}$ & s & $\begin{array}{l}1,81 \\
1,71\end{array}$ & $\begin{array}{l}9,0 \\
\epsilon, 9 \\
4,7\end{array}$ & $\begin{array}{r}16,3 \\
: 18,4 \\
\vdots 19,2\end{array}$ & $\begin{array}{l}1 \\
26 \\
R\end{array}$ & & $\begin{array}{l}\text { No } \\
\text { SI } \\
\text { SI }\end{array}$ & $\begin{array}{r}130 \\
20 \\
6\end{array}$ & $\begin{array}{r}217 \\
38 \\
13\end{array}$ & $\begin{array}{r}227 \\
48 \\
14\end{array}$ & & $\begin{array}{l}1,05 \\
1,33 \\
1,08\end{array}$ & i & $\begin{array}{r}45 \\
13 \\
2\end{array}$ & $\begin{array}{l}11 \\
10 \\
3\end{array}$ & & & $\begin{array}{l}31 \\
33 \\
.17\end{array}$ & $\begin{array}{l}21 \\
, 36 \\
15\end{array}$ & , 30 \\
\hline $\begin{array}{l}1900\left(P_{0}\right) \\
\text { "layo }\end{array}$ & $\begin{array}{l}1,36 \\
R \\
2,49\end{array}$ & $\begin{array}{l}2,3 \\
96 \\
38\end{array}$ & $\begin{array}{r}13 \\
18 \\
110 \\
\end{array}$ & $\begin{array}{l}12,36 \\
1,47 \\
1,7,87 \\
-\end{array}$ & $\begin{array}{l}2,141 \\
1,991 \\
1,891\end{array}$ & $\begin{array}{l}443 \\
231 \\
13.6 \\
\cdots-6\end{array}$ & & $\begin{array}{l}373 \\
396\end{array}$ & $\begin{array}{l}0,83 \\
1,61 \\
2,92\end{array}$ & $\begin{array}{r}17 \\
12 \\
5\end{array}$ & $\begin{array}{l}8 \\
3 \\
0\end{array}$ & $\begin{array}{r}110 \\
71 \\
46 \\
-46\end{array}$ & $\begin{array}{l}25 \\
15 \\
10\end{array}$ & $\begin{array}{l}S \\
s \\
M\end{array}$ & & $\begin{array}{l}7,3 \\
4,6 \\
2,9\end{array}$ & $\begin{array}{r}13,4 \\
16,1 \\
17,4\end{array}$ & $\begin{array}{l}6 \\
45 \\
R\end{array}$ & & $\begin{array}{l}\text { si } \\
\text { si } \\
\text { si }\end{array}$ & $\begin{array}{r}123 \\
19 \\
0\end{array}$ & $\begin{array}{r}184 \\
39 \\
3\end{array}$ & $\begin{array}{r}192 \\
45 \\
6 \\
\end{array}$ & $\begin{array}{l}0,49 \\
0\end{array}$ & $\begin{array}{l}1,19 \\
2\end{array}$ & ? & $\begin{array}{r}10 \\
0\end{array}$ & $\begin{array}{c}43 \\
13 \\
1\end{array}$ & $\begin{array}{l}0,70 \\
0,70 \\
0\end{array}$ & $\begin{array}{l}1,00 \\
1,30 \\
1,00\end{array}$ & $\begin{array}{l}0,73 \\
0,37 \\
-\end{array}$ & $\begin{array}{c}0,22 \\
0,28 \\
-\end{array}$ & $\begin{array}{l}0,22 \\
0,20 \\
0,17\end{array}$ \\
\hline $\begin{array}{l}\text { anodo } \\
\text { crnoqueo }\end{array}$ & $\begin{array}{c}1,51 \\
p \\
2,10\end{array}$ & $\begin{array}{l}20,4 \\
61 \\
81\end{array}$ & $\begin{array}{l}13 \\
16 \\
110\end{array}$ & $\begin{array}{l}12,13 \\
14,26 \\
17,09\end{array}$ & $\begin{array}{l}2,178 \\
2,096 \\
2,037\end{array}$ & $\begin{array}{l}463 \\
255 \\
158\end{array}$ & $\begin{array}{l}1390 \\
1529 \\
1577\end{array}$ & $\begin{array}{l}325 \\
312 \\
302\end{array}$ & $\begin{array}{l}0,70 \\
1,22 \\
1,98\end{array}$ & $\begin{array}{l}16 \\
16 \\
12\end{array}$ & $\begin{array}{l}7 \\
8 \\
6\end{array}$ & $\begin{array}{l}83 \\
88 \\
79\end{array}$ & $\begin{array}{l}38 \\
31 \\
27 \\
\end{array}$ & $\begin{array}{l}0 \\
0 \\
G\end{array}$ & $\begin{array}{l}1,96 \\
1,89\end{array}$ & $\begin{array}{l}7,3 \\
4,9 \\
3,5\end{array}$ & $\begin{array}{l}12,9 \\
12,9 \\
12,6\end{array}$ & $\begin{array}{l}0 \\
1 \\
4\end{array}$ & & $\begin{array}{l}\text { No } \\
\text { No } \\
\text { SI }\end{array}$ & $\begin{array}{l}211 \\
72 \\
22\end{array}$ & $\begin{array}{r}250 \\
108 \\
39\end{array}$ & $\begin{array}{r}289 \\
109 \\
39\end{array}$ & $\begin{array}{l}0,84 \\
0,67 \\
0,36\end{array}$ & $\begin{array}{l}1,16 \\
1,01 \\
1,00\end{array}$ & $\begin{array}{r}49 \\
23 \\
9\end{array}$ & $\begin{array}{l}80 \\
34 \\
15\end{array}$ & $\begin{array}{l}80 \\
35 \\
.16\end{array}$ & & $\begin{array}{l}1,00 \\
1,03 \\
1,07\end{array}$ & & & $\begin{array}{l}0,24 \\
0,32 \\
0,11\end{array}$ \\
\hline obas (Na) & $\begin{array}{l}1,47 \\
P \\
1,84\end{array}$ & $\begin{array}{l}23, \\
66 \\
91\end{array}$ & $\begin{array}{l}13 \\
16 \\
110\end{array}$ & $\begin{array}{l}12,18 \\
14,36 \\
17,28\end{array}$ & $\begin{array}{r}2,159 \\
2,154 \\
2,107\end{array}$ & $\begin{array}{l}456 \\
262 \\
162\end{array}$ & $\begin{array}{l}1368 \\
1572 \\
1621\end{array}$ & $\begin{array}{l}33 r \\
326 \\
324\end{array}$ & $\begin{array}{l}0,73 \\
1,22 \\
2,00\end{array}$ & $\begin{array}{l}14 \\
12 \\
14\end{array}$ & $\begin{array}{l}4,5 \\
4 \\
5\end{array}$ & $\begin{array}{l}83 \\
73 \\
82\end{array}$ & $\begin{array}{l}42 \\
35\end{array}$ & $\theta$ & $\begin{array}{l}2,00 \\
1,91\end{array}$ & $\begin{array}{l}7,1 \\
4,7 \\
3,0\end{array}$ & $\begin{array}{l}13,2 \\
13,3 \\
14,2\end{array}$ & R & & $\begin{array}{l}\text { No } \\
\text { S1 } \\
\text { S1 }\end{array}$ & $\begin{array}{r}203 \\
73 \\
19\end{array}$ & $\begin{array}{r}263 \\
114 \\
31\end{array}$ & $\begin{array}{r}297 \\
123 \\
39\end{array}$ & $\begin{array}{l}0,78 \\
0,66 \\
0,61\end{array}$ & $\begin{array}{l}1,13 \\
1,00 \\
1,22\end{array}$ & $\begin{array}{r}43 \\
21 \\
8\end{array}$ & $\begin{array}{l}57 \\
33 \\
12\end{array}$ & $\begin{array}{l}62 \\
35 \\
13\end{array}$ & $\begin{array}{l}0,75 \\
0,84 \\
0,67\end{array}$ & $\begin{array}{l}1,09 \\
1,06 \\
1,00\end{array}$ & , 428 & $\begin{array}{l}0,22 \\
0,29 \\
0,39\end{array}$ & $\begin{array}{l}0.21 \\
0,28 \\
0,33\end{array}$ \\
\hline
\end{tabular}


CUADRO 9

De los ensayos subre los morteros de la Serie II

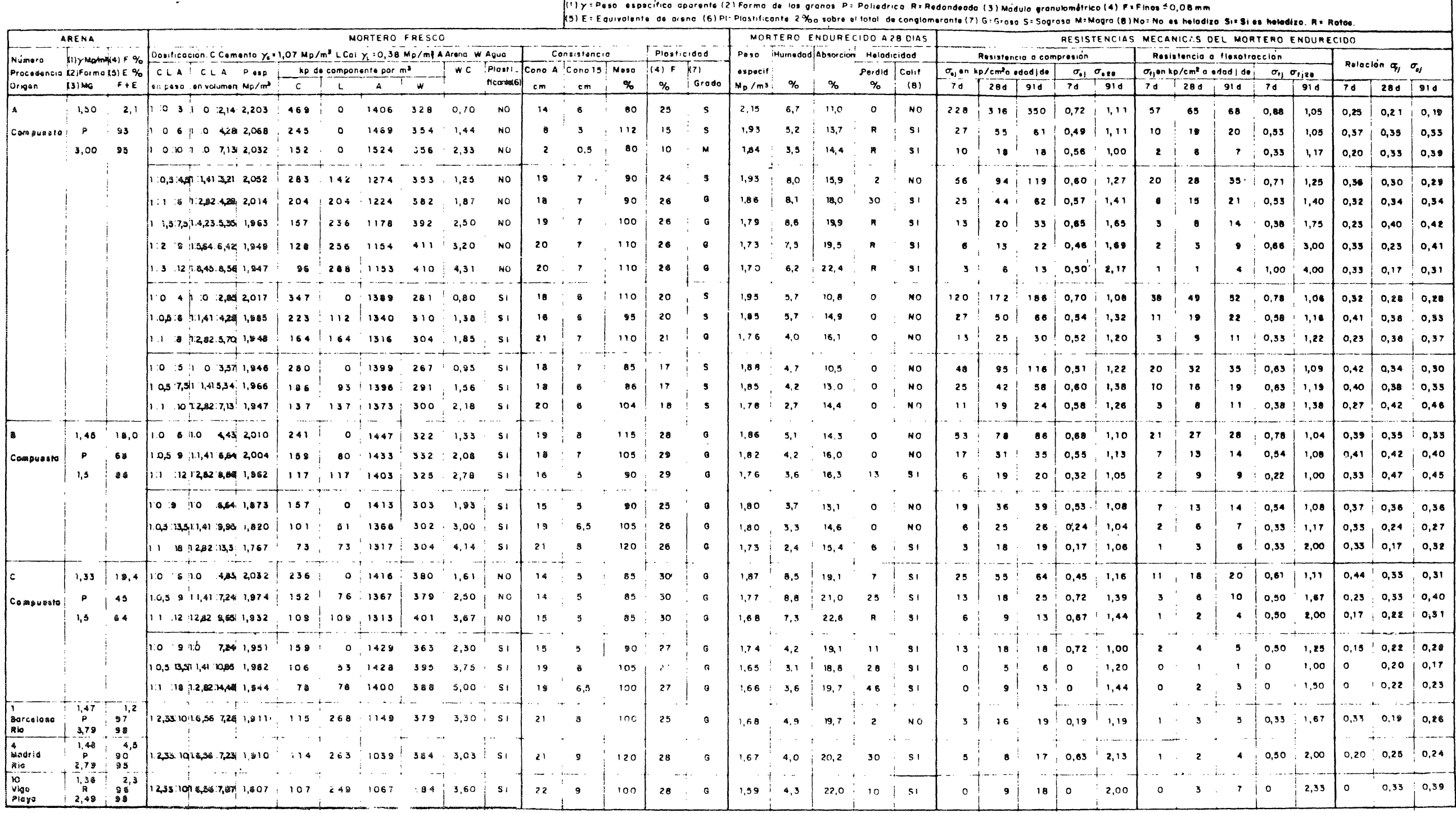




\subsection{Plasticidad del mortero fresco}

En la Norma MV 201-1972, no se define el concepto de plasticidad del mortero fresco, ni un método para medirla. Técnicos y albañiles designan como plasticidad la propiedad del mortero fresco de la que depende su aptitud para poder extender la tortada, restregar el ladrillo y rellenar completamente las juntas: llagas y tendeles.

Se ha intentado medirla mediante un método inspirado en la cuchara de Casagrande para determinar el límite plástico de una arcilla, colocando mortero en un recipiente, haciendo una acanaladura y sometiéndolo a sacudidas. No se han obtenido resultados que fuesen comparables con lo que un albañil experimentado entiende por plasticidad.

El ensayo de extruir por una tobera el mortero fresco incluido en un recipiente a presión, tampoco parece tener interés.

Se ha comprobado que la calificación de la plasticidad de un mortero por el albañil, concuerda bastante con el contenido de finos menores de $0,08 \mathrm{~mm}$ de la mezcla seca: cemento, eventualmente cal, y arena; y que su consistencia debe estar comprendida entre unos limites, que varian de unas mezclas a otras.

También se ha comprobado que un mortero fresco de plasticidad conveniente tiene pequeña segregación de agua, lo que hace más importante el estudio de la hidrofilia, o retentividad del agua de amasado de los morteros frescos, ya que cuando ésta es baja el mortero tiene plasticidad magra, y por consiguiente es inadecuado para sentar ladrillo.

El contenido de finos de la mezcla seca, y la calificación de su plasticidad figuran en el Anejo 3 de este Estudio. Los de los 36 morteros de la Serie I se presentan en el Cuadro 8, y los de los 29 morteros de la Serie II, en el Cuadro 9.

En la Propuesta del Capitulo 3, de la Norma se define la plasticidad del modo indicado, y en función del grado de plasticidad exigido en el Pliego de Prescripciones Particulares del Proyecto, se imponen límites de contenido de finos de la mezcla seca, que son los mismos de la Norma actual, ya que se han mostrado concordantes con las estimaciones del grado de plasticidad.

\subsection{Fabricación de las probetas de ensayo}

Con cada tipo de mortero se fabricaron nueve probetas prismáticas de $4 \times 4 \times 16 \mathrm{~cm}^{3}$, rellenando tres moldes triples de acero convenientemente engrasados. La compactación del mortero en los moldes se efectuó comprimiendo con una espátula, y golpeando después los moldes diez veces contra una mesa de mármol, y se enrasó finalmente con una regla metálica. La consistencia de los morteros confeccionados aconsejó este método de compactación como el más conveniente.

Los moldes llenos se almacenaron en cámara con $95 \%$ de humedad relativa y temperatura de $21 \pm 2^{\circ} \mathrm{C}$, en la que se mantuvieron 24 horas, desmoldando después las probetas. Tres probetas se pesaron seguidamente y con este peso se obtuvo el peso especifico aparente inicial del mortero fraguado. Las nueve probetas desmoldadas se conservaron en cámara húmeda hasta su ensayo.

A partir del peso especifico aparente inicial del mortero fraguado, y del peso especifico aparente en estado suelto de los conglomerantes: cemento y cal en su caso, y de la arena empleada. se calcularon los contenidos de los componentes del mortero en $\mathrm{kg} / \mathrm{m}^{3}$, se obtuvo la dosificación en partes en volumen. 
Los resultados figuran en el Anejo 3 de este estudio. Los de los 36 morteros de la Serie I se resumen en el Cuadro 8 y los de los 29 morteros de la Serie II en el Cuadro 9.

En la figura 5 se presenta la relación entre el contenido de cemento y la relación en peso cemento : arena. En la figura 6 la relación entre las dosificaciones en peso y en volumen.

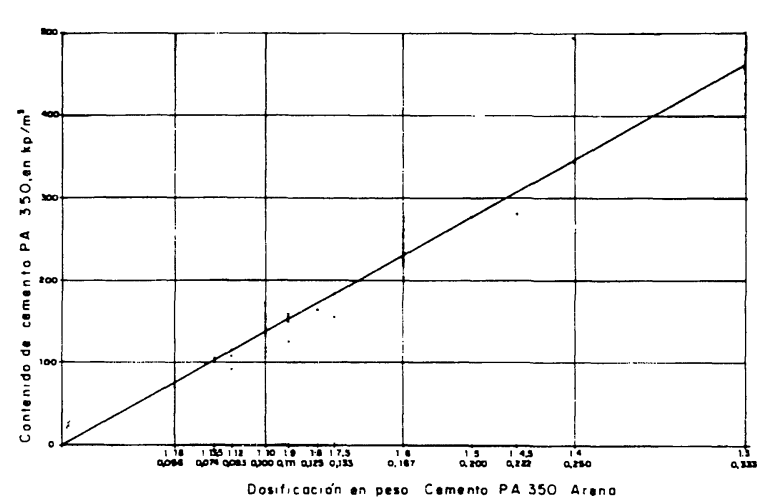

Fig. 5.-Relación contenido de cemento: dosificación en peso.

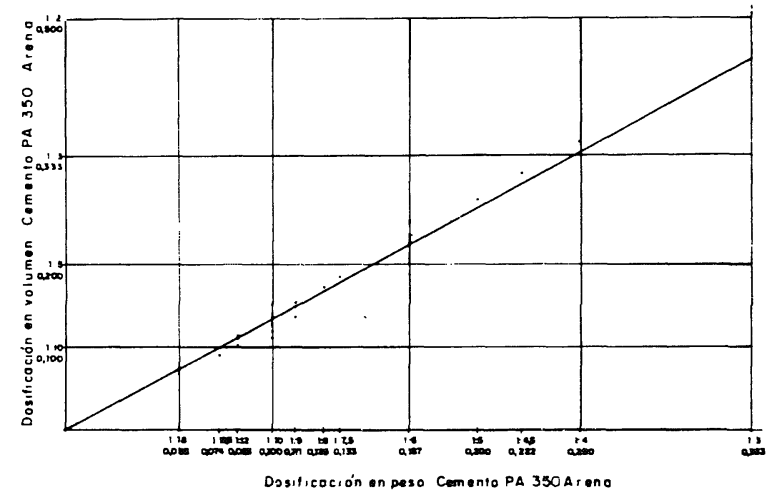

Fig. 6.- Relación dosificación en volumen: dosificación en peso.

\subsection{Prescripciones sobre la confección de morteros}

Las prescripciones, que figuran en el articulo 3.3. de la Propuesta de Revisión, fueron establecidas por el Grupo de Trabajo, después de estudiar la influencia de la dosificación en las propicdades del mortero fraguado, que figura en 4.6.

Las conclusiones a que se llegé, obligaron a incluir el articulo 3.3.1. Dosificación del mortero, siguiendo los criterios adoptados de no especificar dosificación sino contenido de cemento, y establecer la dosificación en la obra realizando la experimentación necesaria para verificar que el mortero cumple con las especificaciones.

El Grupo de Trabajo redactó además el artículo A.3 del Apéndice A en el que se reune todo aquello que tiene carácter de recomendación, pero que resulta útil para la determinación experimental de la dosificación.

El artículo 3.3.2 referente al amasado del mortero se ha redactado sin modificar esencialmente, lo que se indica en la Norma actual, pero resaltando que el amasado a mano requiere autorización.

Finalmente en el artículo 3.3.3 el Grupo de Trabajo ha sido unánime en prohibir el rebatido de mortero, y puntualizar mejor lo referente al tiempo de utilización.

\section{CAPITULO 4. EL MORTERO ENDURECIDO}

\subsection{Ensayos físicos}

De las nueve probetas prismáticas confeccionadas con cada uno de los $36+29$ tipos de mortero, tres probetas se mantuvieron en camara húmeda hasta 28 dias y se sometieron a las siguientes operaciones:

- Pesado, para determinar el peso especifico aparente de los 28 dias y compararlo con el de 24 horas.

- Desecacion, en estufa a $110^{\circ} \mathrm{C}$ hasta peso constante, determinando la humedad contenida. 
- Inmersión en agua a $21 \pm 2^{\circ} \mathrm{C}$ hasta saturación, caracterizada por peso constante, con un mínimo de 7 dias, determinando la absorción del mortero endurecido.

- Ensayo de heladicidad, sometiendo la probeta saturada a 20 ciclos de congelado y deshielo, consistente cada ciclo en permanencia en cámara de congelado a $-20 \pm 2^{\circ} \mathrm{C}$ durante 6 horas, y deshielo en agua durante un mínimo de 18 horas y un máximo de 66 horas. Las probetas se observaron después de cada ciclo, anotando los eventuales desperfectos; se desecaron después del último ciclo y se pesaron, obteniendo por diferencia la pérdida de peso en el ensayo de heladicidad. El mortero se calificó de NO heladizo si no hubo grietas o roturas y la pérdida de peso no fue superior a $3 \%$. En caso contrario la calificación fue de SI heladizo.

Los resultados figuran en el Anejo 3 de este Estudio. Los de los 36 tipos de morteros de la Seric I se resumen en el Cuadro 8 y los de los 29 de la Serie II en el Cuadro 9.

\subsection{Humedad y absorción}

Es conocido que una pequeña cantidad de agua de amasado del mortero se combina con el cemento y el resto queda en los huecos del mortero sin rellenarlos absolutamente. Este agua se ha evaporado en parte durante los 28 dias de conservación de las probetas en cámara húmeda.

La humedad que conservan las probetas de los morteros sin cal, Serie I a los 28 dias de conservación en cámara húmeda, depende mucho de la dosificación de cemento, pero poco de la clase de arena. La humedad en valor medio obtenida para cada una de las dosificaciones ha sido:

- Dosificación 1:3 7,3\%.

- Dosificación 1:6 4,9\%.

- Dosificación 1: $103,2 \%$.

En los morteros con cal de la Serie II, la humedad a los 28 dias es aigo mayor y depende mucho menos de la relación cemento: arena.

El contenido de huecos de los morteros sin cal, Serie I, que se deduce de los resultados de absorción señalados en el Cuadro 8, ha variado poco con la dosificación de cemento, y mucho con la clase de arena. La absorción en valor medio obtenido en los diferentes grupos de arenas se refleja en el Cuadro 10.

CUADRO 10

Absorción de los morteros ensayados

\begin{tabular}{|c|c|}
\hline Clases de arena & $\begin{array}{c}\text { Absorcion } \\
\text { media } \\
\frac{z}{8}\end{array}$ \\
\hline $\begin{array}{l}\text { Arenas de rio o cantera, con bajo contenido de } \\
\text { finos (no } 1,2,3,4 \text { y } 7)\end{array}$ & 11,3 \\
\hline $\begin{array}{l}\text { Areras de machaqueo, con alto contenido de finos } \\
\text { no arcillosos (no } 11 \text { y } 12 \text { ) }\end{array}$ & 13,1 \\
\hline $\begin{array}{l}\text { Arenas de cantera, con alto contenido ae finos } \\
\text { arcillosos (no } 5 \mathrm{y} \text { 6) }\end{array}$ & 18,1 \\
\hline $\begin{array}{l}\text { Arenas de playa, (no } 8,9 \text { y } 10 \text { ) (con irregularidad } \\
\text { mayor con otros grupos) }\end{array}$ & 18,5 \\
\hline
\end{tabular}


La capilaridad del mortero en las juntas de la fábrica, se sabe sin embargo que disminuye con el contenido de cemento (32). No ha sido estudiada aqui esta propiedad, que mereceria una investigación especial.

En los morteros con cal, Serie II, la absorción que se refleja en el Cuadro 9, es algo mayor que en los correspondientes sin cal, y asi mismo es considerablemente mayor en las arenas con finos arcillosos.

\subsection{Anheladicidad}

En las fábricas vistas en exteriores en casi toda la Península, especialmente en toda la meseta central de clima frio, la resistencia a las heladas es importante en el mortero para garantizar la durabilidad de las fábricas (33), especialmente cuando están en contacto con el suclo. o en la coronación de muros no protegidos por amplios aleros.

En los morteros sin cal de la Serie I la anheladicidad. en función de la dosificación de cemento, se ha obtenido en los siguientes porcentajes:

- Dosificación 1:3 75\%. Fallan con las arenas n.os 5, 8 y 10.

- Dosificación 1:6 42\%. Fallan además con las arenas n.» 4. 6, 9 y 12.

- Dosificación 1:10 0\%. Fallan con todas las arenas.

En los morteros de la Serie II la anheladicidad se obtiene en más casos, con dosificaciones bajas de cemento, siendo favorable la adición de cal y especialmente la inclusión de aditivo plastificante. excepto con arena de alto contenido de finos arcillosos que fallaron en todos los casos.

La anheladicidad se asocia a altos contenidos de cemento, y depende mucho de la clase de arena (34), (35). especialmente de su bajo contenido de finos arcillosos, pero como hay excepciones, cuando se exija en las Prescripciones Técnicas Particulares del Proyecto deberá verificarse mediante ensayos.

\subsection{Ensayos mecánicos}

Con las seis probetas restantes de cada uno de los $36+29$ tipos de mortero, conservadas en cámara húmeda hasta su ensayo, se determinaron las resistencias a flexotracción y compresión, sobre dos probetas, en cada una de las edades de 7, 28 y 91 días.

El cnsayo, y la obtención de resultados, se realizaron según la Norma UNE 7205, ya que la Norma UNE 7270, a que hace referencia la Norma MV 201-1972 no ha sido publicada.

Los resultados en $\mathrm{kp} / \mathrm{cm}^{2}$, y las relaciones entre ellos, se reflejan en el Anejo 3 de este Estudio. Los de los 36 tipos de mortero de la Serie I se resumen en el Cuadro 8, y los de los 29 tipos de la Serie II en el Cuadro 9. La clasificación en grupos de los morteros por su resistencia a compresión a 28 dias figura en el Cuadro 11.

\subsection{Resistencia a compresión a 28 dias}

La resistencia a compresión de un mortero a 28 dias es la propiedad más indicativa de su comportamiento en las fábricas de ladrillo ejecutadas con él. Se relaciona, aunque no linealmente, con otras propiedades del mortero endurecido: anheladicidad, impermeabilidad, adherencia al ladrillo, etc. 
C U A D RO 11

Resistencia a compresión a 28 dias de los morteros ensayados

\begin{tabular}{|c|c|c|c|c|}
\hline \multirow{2}{*}{$\begin{array}{c}\text { Resistencia a } \\
\text { compresión a 28 días } \\
\sigma_{\mathrm{C}} \\
\mathrm{kp} / \mathrm{cm}^{2}\end{array}$} & \multicolumn{3}{|c|}{ Resultados de los morteros ensavados: } \\
\cline { 2 - 5 } & \multicolumn{3}{|c|}{ Número } & Rateo \\
\cline { 2 - 5 } & Serie I & Serie II & Total & \\
\hline 300 & 2 & 1 & 3 & 5 \\
$199-150$ & 6 & 0 & 6 & 9 \\
$149-100$ & 1 & 1 & 2 & 3 \\
\hline $99-50$ & 7 & 0 & 7 & 11 \\
$49-25$ & 5 & 6 & 11 & 17 \\
$<25$ & 9 & 6 & 12 & 18 \\
\hline Total & 36 & 29 & 24 & 37 \\
\hline
\end{tabular}

Por esta razón, en muchas Normas se establecen tipos de morteros definidos por su resistencia a compresión a 28 dias, $\sigma_{i}$. Entre cllas lo hacen asi las tres siguientes:

- La Norma MV 201-1972 (1) que clasifica los morteros en seis tipos, siguiendo una serie geométrica de razón 2 , que empieza con la resistencia de $5 \mathrm{kp} / \mathrm{cm}^{2}$, y llega a $160 \mathrm{kp} / \mathrm{cm}^{2}$.

- Las recomendaciones CIB (10), en que los tipos son cuatro, también según una serie geométrica de razón 2, con los valores de resistencia, en MPa: 2,5; 5; 10 y 20.

- La Norma ASTM 270-80a (12), con cinco tipos, siendo los valores de resistencia en MPa: 0,$5 ; 2,4 ; 5,2 ; 12,4 ; 17,2$.

Los resultados de los ensayos, clasificados en el Cuadro 11, reflejan claramente la mejora de la resistencia de los cementos que se produjo al comenzar el decenio transcurrido desde la publicacion de la Norma MV 201-1972, y que dió lugar al aumento de las resistencias exigidas en el Pliego de 1964, sustituyéndose por las del Pliego RC-75.

El Grupo de Trabajo, a la vista de los resultados de los ensayos decidió elevar los límites de resistencia que definen los tipos, estableciendo las resistencias en $\mathrm{MPa}$, y adoptando las de las Recomendaciones $\mathrm{CIB}$, que representan una elevación del $25 \%$ respecto de las actuales. Esta elevación es menor que la producida en la resistencia del cemento entre ambos Pliegos, que referida al cemento portland ordinario P-250 en 1964, y al cemento PA-350 común a partir de 1977 (6), fue del $40 \%$.

La decisión incluye suprimir los tipos de resistencia inferior a 2,5 $\mathrm{MPa}$, que a la vista de los ensayos sólo se obtiene con morteros de muy deficiente plasticidad o un alto contenido de cal. Con coste no superior puede alcanzarse siempre la resistencia de $2,5 \mathrm{MPa}$ empleando un contenido de cemento igual o superior a $200 \mathrm{~kg} / \mathrm{m}^{3}$, que se juzga minimo para los morteros de fábricas resistentes, como se ve en 4.6.

No es este el criterio de ASTM 270, que mantiene un mortero con resistencias $0.5 \mathrm{MPa}$, con bajo contenido de cemento y muy alto de cal. pero sólo se permite para muros y particiones interiores. 


\subsection{Influencia de la dosificación}

La dosificación del mortero tiene relación con la resistencia a compresión a 28 dias. Esta relación puede verse tanto en la dosificación en peso, como en la dosificación en volumen. pero resulta ser mucho más directa si se refiere al contenido de cemento del mortero.

El Grupo de Trabajo después de un análisis cuidadoso decidió que en la propuesta de revisión del Capitulo de la Norma, el contenido de cemento figure como una de las especificaciones del mortero, y que por el contrario no se especifique ni dosificación en peso ni en volumen. Una u otra, la que vaya a emplearse en la obra, se calculará, antes de comenzar los trabajos en ésta, de modo experimental, realizando morteros que se ensayarán para determinar las propiedades exigidas en la especificación.

Esto, por otra parte, es lo que se viene realizando en los hormigones estructurales. La antigua exigencia de dosificación se sustituyó hace ya decenios por una especificación de resistencia y otra de contenido minimo de cemento.

Para analizar con mayor profundidad la influencia del contenido de cemento del mortero en su resistencia a compresión a 28 días, los resultados de los Cuadros 8 y 9 se han transcrito en el Cuadro 12. En éste se pone en relación la resistencia con el contenido de cemento del mortero, en valores máximos, medio y minimo, determinados en los tipos de cada grupc de resistencias.

CUADRO 12

Influencia del contenido de cemento

\begin{tabular}{|c|c|c|c|c|c|c|c|}
\hline \multirow{2}{*}{$\begin{array}{c}\text { Resistencia a } \\
\text { compresión a } \\
28 \text { dias } \\
u_{\mathrm{c}} \\
\mathrm{k} / \mathrm{cm}^{2}\end{array}$} & \multirow{2}{*}{$\begin{array}{l}\text { Rateo de } \\
\text { los mor- } \\
\text { teros en } \\
\text { sayados } \\
\quad \therefore\end{array}$} & \multicolumn{3}{|c|}{$\begin{array}{r}\text { Contenido de cemerito } \\
\mathrm{C}\end{array}$} & \multicolumn{3}{|c|}{ Relacion $\frac{{ }^{\circ} \mathrm{C}}{\mathrm{C}}$} \\
\hline & & $\begin{array}{l}\text { Niśximo } \\
\mathrm{ks} / \mathrm{m}^{3}\end{array}$ & $\begin{array}{l}\text { Neciio } \\
\mathrm{kg} / \mathrm{ral}^{3}\end{array}$ & $\begin{array}{l}\text { Ninizio } \\
\mathrm{kg} / \mathrm{ni}^{3}\end{array}$ & $\begin{array}{l}\text { Máximo } \\
\mathrm{kp} / \mathrm{cm}^{2} \\
\mathrm{~kg} / \mathrm{m}^{3}\end{array}$ & $\begin{array}{l}\text { Medio } \\
\mathrm{kp} / \mathrm{cm}^{2} \\
\mathrm{~kg} / \mathrm{m}^{3}\end{array}$ & $\begin{array}{l}\mathrm{M}=\mathrm{nimo} \\
\mathrm{kp} / \mathrm{cm}^{2} \\
\mathrm{~kg} / \mathrm{m}^{3}\end{array}$ \\
\hline$\geq 300$ & 5 & 503 & 485 & 469 & 0,702 & 0,688 & $0, \in 74$ \\
\hline $299-200$ & 9 & 478 & 459 & 428 & 0,582 & 0,542 & 0,491 \\
\hline $199-150$ & 3 & 443 & 395 & $3 \div 7$ & 0,496 & 0,656 & 0,415 \\
\hline $149-100$ & 11 & 425 & 328 & 255 & 0,442 & $\therefore 58$ & 0,300 \\
\hline $99-$ & 17 & 283 & 243 & $1 \%$ & 0,339 & 0,280 & 0,224 \\
\hline $49-$ & 18 & 236 & 191. & 157 & 0,270 & 0,204 & 0,152 \\
\hline 25 & 37 & 202 & 131 & 73 & 0,247 & 0,101 & 0,022 \\
\hline
\end{tabular}

De estos resultados se deduce que la relación entre la resistencia a compresión y su contenido de cemento, no es lineal. La resistencia crece mucho más rápidamente que el contenido de cemento, es decir el cemento es poco eficaz con contenidos bajos.

No parece conveniente confeccionar morteros con un contenido de cemento inferior a $200 \mathrm{~kg} / \mathrm{m}^{3}$, ya que la resistencia de estos morteros será en muchos casos inferior a la minima de $2.5 \mathrm{MPa}$.

\subsection{La relación agua : cemento}

Los resultados de los ensayos de los morteros muestran además la conocida ley existente entre la relación agua: cemento y la resistencia a compresión. En la figura 7 se han representado los 
resultados de los $36+29$ morteros ensayados, y en ella se han marcado las rectas de separación entre los cuatro tipos M2, M5, M10 y M20, que figuran en la Propuesta.

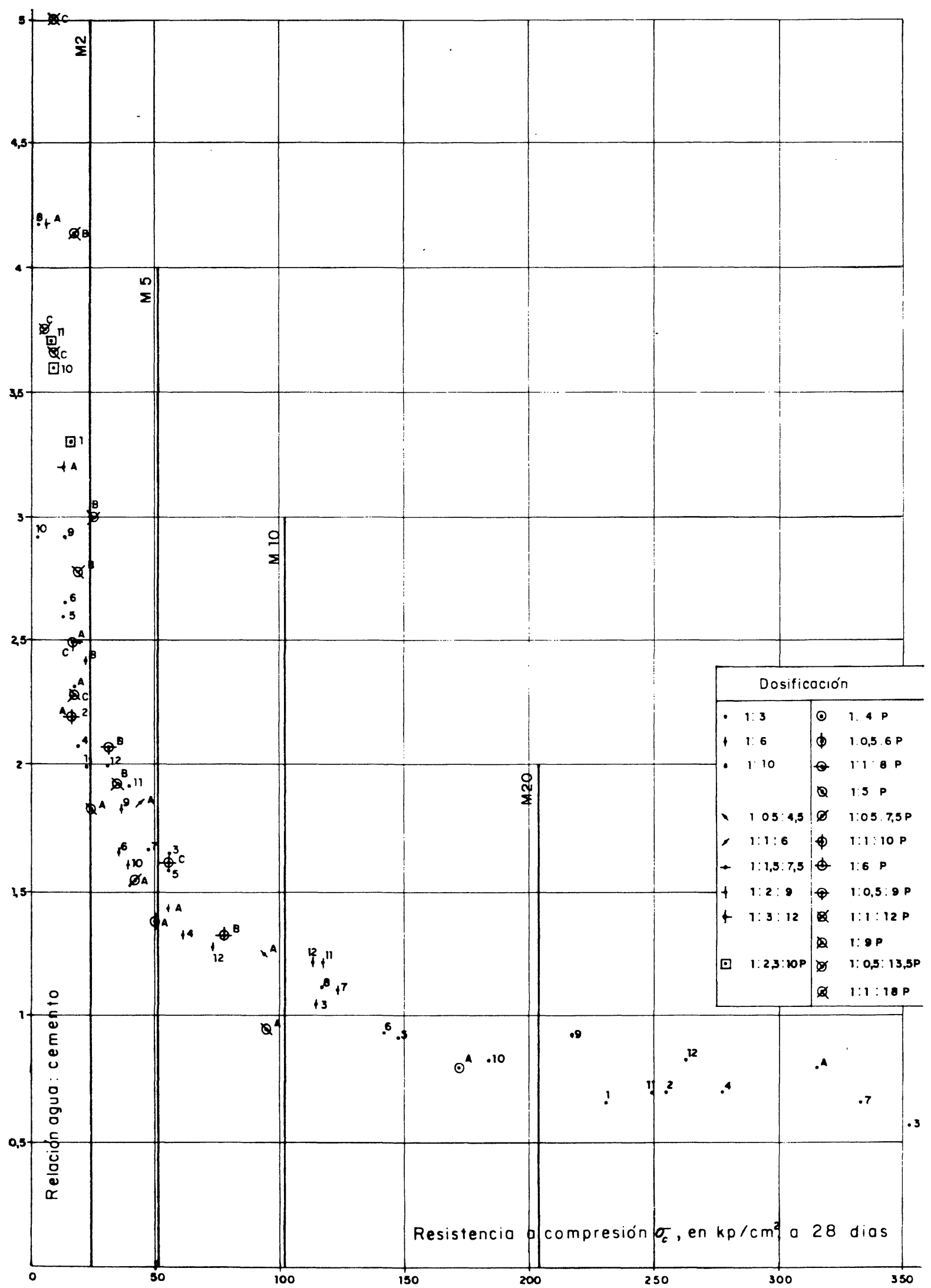

Fig. 7.-Influencia de la relación agua : cemento en la resistencia a compresión. 
La relación agua: cemento de los morteros para fábricas de ladrillo es necesariamente alta para conseguir la plasticidad requerida. Depende de las caracteristicas de la arena y del contenido de cemento, como puede verse en el Cuadro 13, que se deduce esquemáticamente de los resultados de los ensayos realizados, y en él se incluye una propuesta de contenido minimo de cemento.

CUADRO 13

Relación agua: cemento según los tipos de mortero

\begin{tabular}{|c|c|l|c|c|}
\hline $\begin{array}{c}\text { Tipo de } \\
\text { mortero }\end{array}$ & $\begin{array}{l}\text { Rateo de los } \\
\text { morteros ensa } \\
\text { yados. }\end{array}$ & $\begin{array}{l}\text { Caracteristi- } \\
\text { Cas de la } \\
\text { arena }\end{array}$ & $\begin{array}{c}\text { Relación } \\
\text { acua: cemento }\end{array}$ & $\begin{array}{c}\text { Contenido } \\
\text { de } \begin{array}{c}\text { cemento } \\
\mathrm{kcj} / \mathrm{mi}^{3}\end{array}\end{array}$ \\
\hline M20 & 14 & Buenas & $0,7 \pm 0,1$ & 400 \\
\hline M10 & 14 & $\begin{array}{l}\text { Deficientes } \\
\text { Buenas }\end{array}$ & $1,0 \pm 0,1$ & $\begin{array}{l}400 \\
300\end{array}$ \\
\hline M2 & 18 & $\begin{array}{l}\text { Deficientes } \\
\text { Buenas }\end{array}$ & $1,4 \pm 0,2$ & $\begin{array}{l}300 \\
250\end{array}$ \\
\hline $\begin{array}{l}\text { Deficientes } \\
\text { Bnaciecuado }\end{array}$ & 37 & $1,8 \pm 0,2$ & $\begin{array}{l}250 \\
200\end{array}$ \\
\hline
\end{tabular}

El Grupo de Trabajo juzgó que no era necesario imponer ninguna condición a la relación agua : cemento en las especificaciones del mortero de la Propuesta de Revisión en el Capitulo 3 de la Norma, ya que van implícitas en lo que se especifica.

\subsection{Resistencia a flexotracción}

En el comportamiento de las fábricas de ladrillo a compresión y a cortadura, se producen tensiones de tracción, $\mathrm{y}$ por ello tiene influencia no solamente la resistencia a compresión del

CUADRO 14

Relación entre las resistencias a flexotracción y a compresión

\begin{tabular}{|c|c|c|c|c|c|c|c|c|}
\hline \multirow{2}{*}{\multicolumn{2}{|c|}{$\begin{array}{l}\text { Resistencia } \\
\text { a compresién } \\
\text { a } 28 \text { dias }\end{array}$}} & \multirow{2}{*}{$\begin{array}{l}\text { Rateo de } \\
\text { los mor- } \\
\text { teros en } \\
\text { sayados }\end{array}$} & \multicolumn{3}{|c|}{$\begin{array}{l}\text { Resistencia a flexotracción } \\
\sigma_{f}, \text { a } 28 \text { días }\end{array}$} & \multicolumn{3}{|c|}{ Relacion $\sigma_{f}: \sigma_{C}$} \\
\hline & & & Máxima & Media & Mínima & Máxima & Media & N'ínima \\
\hline \multicolumn{2}{|c|}{$\begin{array}{c}\sigma_{\mathrm{C}} \\
\mathrm{kp} / \mathrm{cm}^{2}\end{array}$} & $\%$ & $\mathrm{kp} / \mathrm{cm}^{2}$ & $\mathrm{kp} / \mathrm{cm}^{2}$ & $\mathrm{kp} / \mathrm{cm}^{2}$ & & & \\
\hline & $\geq 300$ & 5 & 65 & 63 & 59 & 0,25 & 0,22 & 0,18 \\
\hline 299 & -200 & 9 & 60 & 54 & 45 & 0,31 & 0,23 & 0,21 \\
\hline 199 & -150 & 3 & 49 & 45 & 40 & 0,32 & 0,27 & 0,22 \\
\hline 149 & -100 & 11 & 45 & 36 & 30 & 0,32 & 0,29 & 0,26 \\
\hline 99 & -50 & 19 & 32 & 20 & 13 & 0,38 & 0,30 & 0,23 \\
\hline 49 & -25 & 18 & 18 & 13 & 9 & 0,42 & 0,33 & 0,26 \\
\hline & 25 & 37 & 13 & 5 & 0 & 0,47 & 0,26 & 0 \\
\hline
\end{tabular}


mortero, sino también su resistencia a flexotracción, que es un indice de su resistencia a tracción.

En los Cuadros 8 y 9 figuran todos los resultados de los ensayos a flexotracción realizados, y las relaciones entre la resistencia a flexotracción y a compresión en las edades de 7. 28 y 91 dias. La comparación de los resultados a 28 dias, por grupos de resistencia a compresión se presenta en el Cuadro 14.

El Grupo de Trabajo a la vista de estos resultados ha redactado las exigencias de resistencia a flexotracción a 28 dias. para los cuatro tipos de mortero que figuran en la Tabla 3.6 de la Propuesta de Revisión del Capitulo 3 de la Norma.

\section{CAPITULO 5. CONSIDERACIONES FINALES}

\subsection{Introducción}

La investigación realizada en el Laboratorio de edificación de la Escuela Técnica Superior de Arquitectura de la Universidad de Navarra, de acuerdo con el programa convenido con el Instituto Eduardo Torroja de la Construcción y del Cemento, sobre los morteros y sus materiales, tanto en su parte experimental. como en la valoración de los resultados de los ensayos. que ha sido el objeto de esta Memoria, no ha sido realmente exhaustiva sino concentrada en aquellas cuestiones que permitieran una propuesta para la actualización del Capitulo 3, Morteros, de la Norma MV 201-1972, Muros resistentes de fábrica de ladrillo.

La propuesta ha sido redactada, y las cuestiones más importantes que han sido objeto de modificación se indican como sigue: Materiales para la confección de morteros en 5.2, Características de los morteros en 5.3 y Condiciones sobre la ejecución en 5.4. En su descripción se hará referencia al articulado de la Propuesta.

En los morteros para fábricas hay varias cuestiones más, que han sido poco investigadas en España, y que merecerian serlo, en parte para perfeccionar la Norma, pero sobre todo para un mejor conocimiento de los morteros y su influencia en el comportamiento de las fábricas de ladrillo. Estas cuestiones se detallan en 5.5 .

\subsection{Los materiales}

Los cementos (3.1.1), como materiales perfectamente conocidos, no han sido objeto de ensayos, salvo el PA-350 empleado en la confección de los morteros de ensayo. La propuesta amplia condiciones de suministro y almacenamiento que son importantes, y faltaban en la Norma actual.

En cales aéreas (3.1.2) han sido ensayadas siete muestras, que han inducido a una modificación de las condiciones exigibles. Tambièn se amplian las exigencias para suministro y almacenamiento.

Las cales hidráulicas (3.1.3) no se han ensayado, por no haber podido obtener muestras, ya que apenas se fabrican actualmente. La propuesta reduce por ello de tres a dos los tipos. moderniza sus condiciones, y amplia las exigencias para suministro y almacenamiento.

En arenas (3.1.4) han sido ensayadas doce muestras, que pueden considerarse como un conjunto representativo de las que en la actualidad se emplean. En algunas se han encontrado deficiencias. que perjudican de modo importante las propiedades de los morteros con ellas fabricados. Han sido estudiadas las condiciones de las arenas, modificando las de granulometria. que se juzgaron inadecuadas, y la del contenido de finos, muy importante y poco cumplida. Se han 
incluido las del contenido de compuestos de azufre y reactividad potencial como los álcalis del cemento, deficiencias poco frecuentes, pero de graves consecuencias cuando existan.

Se prepararon arenas compuestas para el estudio de la influencia de varios factores en las propiedades de los morteros frescos y endurecidos.

Las aguas (3.1.5) no han sido objeto de ensayos y la Propuesta coincide con la Norma. salvo la presentación y algún detalle.

Los aditivos (3.1.6) constituyen un campo complejisimo que no forma parte del estudio. Será muy costosa cualquier investigacion sobre ellos, por el enorme número de aditivos que modifican propiedades varias. La Propuesta precisa un poco más su empleo, pero sin profundizar en el tema.

\subsection{Características de los morteros}

Las caracteristicas de los morteros han constituido la parte más importante del trabajo experimental obligando a modificaciones de entidad en la Propuesta respecto al texto de la Norma.

La especificación del mortero (3.2.1) constituye una novedad, al establecerse preceptivamente por el tipo, función de su resistencia (3.2.5): los conglomerantes y sus contenidos: los aditivos y su dosificación: y optativamente otras propicdades: plasticidad (3.2.2). hidrofilia (3.2.3). anheladicidad (3.2.4), y otras. Se dan indicaciones para establecerlas en los Articulos A.1 y A.2 del Apéndice A de la Propuesta de actualización.

Se abandona por tanto como objeto de especificacion la dosificación, sea en partes en peso o en partes en volumen, que pasa a constituir el conjunto inicial de operaciones de la confección de los morteros (3.3.1), y que se determinará experimentalmente basándose en el cumplimiento de la especificación.

La plasticidad (3.2.2) del mortero fresco fïgura como condicion optativa. basada en el contenido de finos y la consistencia.

La hidrofilia (3.2.3) figura como propiedad optativa, indicando las directrices de su ensayo, que deberá ser objeto de Norma UNE. y sin fijar condiciones, ya que falta experiencia española, no habiendo parecido conveniente transcribir la de la ASTM estadounidense.

La anheladicidad (3.2.4) es también una propiedad optativa de la que se dan las condiciones, pero sólo será exigible cuando en el proyecto se juzgue necesario. También convendrá se redacte una Norma UNE especifica para el ensayo de heladicidad de morteros.

La resistencia (3.2.5) a flexotracción. y especialmente a compresión a 28 dias. han sido objeto de estudio profundo. Esta última propiedad define los cuatro tipos M20, M10, M5 y M2 de morteros que se establecen, y es la propiedad básica, relacionada con las demás del mortero endurecido: anheladicidad, impermeabilidad, adherencia al ladrillo, etc.

\subsection{Condiciones de ejecución}

La dosificacion del mortero (3.3.1), como se ha indicado en 5.3, debera determinarse previamente a los trabajos de confección del mortero, ya que se necesita para el llenado de la amasadora. No figura entre las especificaciones y deberá ser determinada experimentalmente. realizando mezclas de prueba que se someterán a los ensayos de las propiedades especificadas. Indicaciones para ello figuran en el articulo A.3 del Apendice A de la Propuesta de actualizacion. 
El amasado del mortero (3.3.2), mantiene sin modificación esencial el texto de la Norma actual. pero se exige autorización del Director de Obra para el amasado a mano, que actualmente sólo debe permitirse en obras de menor importancia.

El tiempo de utilización (3.3.3) del mortero fresco se puntualiza mejor en el método de establecerlo. Se prohibe el rebatido del mortero.

\subsection{Cuestiones para investigaciones futuras}

Hidrofilia de los morteros frescos para ver su influencia en la plasticidad o sea en las condiciones de su puesta en obra y en las propiedades de los morteros endurecidos y de las fábricas.

Aeroclusión de los morteros, sin y con aditivos aireantes, estudiando su influencia en propiedades varias de los morteros frescos, endurecidos, y de las fábricas.

Capilaridad de los morteros endurecidos y su influencia en las fábricas.

Adherencia entre mortero y ladrillo.

Acción de aditivos anticongelantes, retardadores de fraguado, hidrófugos, etc.

También debe mencionarse la necesidad de redacción y publicación de una serie de normas UNE, a las que se hace referencia en la Propuesta, y otras consecuencia de métodos de ensayo derivados de investigaciones futuras.

\section{B I B L I O G R A F I A}

(1) Norma MV 201-1972: Muros resistentes de fäbrica de ladrillo. Decreto 1324/1972. B.O.E. 1972.05.31. Madrid.

(2) Pliego RC-75: Prescripciones Técnicas Generales para la recepción de cemento. Decreto 1964/1975. B.O.F. 1975.08.28, Madrid.

(3) Pliego de Condiciones Técnicas de la Dirección General de Arquitectura. Orden del Ministerio de la Vivienda de 1973.06.04. B.O.E. 1973.06.13. Madrid.

(4) PG 3: Prescripciones Tecnicas Generales para obras de carreteras y puentes. Orden del Ministerio de Obras Públicas de 1976.02.06, B.O.E. 1976.07.07, Madrid.

(5) PIET 70 Prescripciones: Muros de fábrica. Instituto Eduardo Torroja de la construccion y del cemento, Madrid. 1971.

(6) Criterios para la utilización de cementos incluidos en el Pliego RC-75. Orden del Ministerio de Obras Públicas de 1977.06.13 (B.O.E. 1977.06.20).

(7) J. CALlEJA: Código de buena práctica para la utilización de los cementos del Pliego RC-75. Instituto Eduardo Torroja de la construcción y del cemento, Madrid, 1977.

(8) F. ARREDONDO: Dosificación de hormigones. Instituto Eduardo Torroja de la construcción y del cemento. Madrid 1965

(9) M. VENUAT, M. PAPADAKIS: Control y ensayo de cementos, morteros y hormigones. Urmo, Bilbao. 1966.

(10) International recommendations for masonry structures CIB: Comission W23, Publication 58. Paris. 1981.

(11) ASA A 41.1: Requeriments for masonry: American Standard Association. 1953.

(12) ASTM C 270-80a: Standard Specification for mortar for unit masonry. Annual book of ASTM standards 16. Filadelfia 1981

(13) CP 111-1976 Structural recomendation for load baring walls British Standard Institution: Londres 1972.

(14) DIN 1053 I-1974 Mauerwerk: Berechnung una Ausführung Deutsche Normenausschuss. Berlin 1974.

(15) D.T.U. 20.11: Parois et murs en maçonnerie. Documents Techniques Unifies. Paris, 1978.

MATERIALES DE CONSTRUCCCION. Vol. 34, n." 196, octubre/noviembre/diciembre 1984 
(16) J. LAHUERTA, L. F. RODRIGUEZ: Muros de fábrica de ladrillo. Ministerio de la Vivienda, Madrid, 1962.

(17) J. CASSINELLO: Muros de carga de fábrica de ladrillo. Instituto Eduardo Torroja de la construción y del cemento. Monografia 238, Madrid, 1964.

(18) P. HALLER: Hochlausbau in Backstein. Asociación suiza de fabricantes de ladrillos, Zurich, 1959.

(19) J. I. DAVISON: Development of ASTM Specification for mortar for unit masonry. Masonry. Past and Present. ASTM STP 588, Filadelfia, 1975.

(20) M. VENUAT: Aditivos y tratamientos de morteros y hormigones. Editores Técnicos Asociados. Barcelona, 1972.

(21) A. ORIVOIGOICOECHEA: El contenido de finos de las arenas para hormigones. Propuesta de nuevos limites. Hormigón y Acero 142, Madrid, 1982.

(22) Instrucción EH-80: Proyecto y ejecución de obras de hormigón en masa o armado. Decreto 2252/1982, B.O.E. 1982.09.13, Madrid.

(23) Instrucción EP-80: Proyecto y ejecución de las obras de hormigón pretensado. Decreto 1978/1980, B.O.E. 1980.09.08, Madrid.

(24) J. CALLEJA: Los aditivos y su normalización. XVI Jornada Técnica Alemas. Sindicato de Insdustrias Quimicas, Madrid, 1970.

(25) J. LAHUERTA: Los aditivos en la edificación. XVI Jornada Técnica Alemas. Sindicato de Industrias Quimicas, Madrid, 1970.

(26) Recomendaciones MOP: Empleo de aditivos al hormigón. Ministerio de Obras Públicas, Madrid, 1968.

(27) A. RUIZ DUERTO: El Documento de Idonieidad Técnica. Instituto Eduardo Torroja de la construcción y del cemento, Madrid, 1963.

(28) J. LAHUERTA: Control en las obras de albañileria. Centro de Estudios de Ingenieria y Arquitectura, Bilbao 1971.

(29) J. LAHUERTA: Control de las obras de fábrica. Marco General. Colegio Oficial de Arquitectos, Madrid, 1982.

(30) D. D. WALKER: Accelerated curing of lime-cement mortars Masonry. Past and Present. ASTM, STP 588. Filadelfia, 1975.

(31) A. HUIZER et al.: Field and laboratory using current and proposed porcedures for testing masonry y mortar. Masonry. Past and Present. ASTM, STP 588. Filadelfia, 1975.

(32) H. GRANHOLM: Om vattengenomslag i murade väggar. Curmpers Fölag, Göteborg, 1958.

(33) G.G. LITVAN: Freeze-thaw durability of porous building material. Durability of building materials. ASTM, STP 691, Filadelfia. 1980.

(34) J. E. GILLOTT: Effect of microstructure and composition of limestone, marble, basalt and quartzite aggregate on durability. Durability of building material. ASTM, STP 691. Filadelfia, 1980.

(35) W. F. COLE, F. D. BERESFORD: Influcince of basalt taggregate on durability of building material. ASTM, STP 691. Filadelfia, 1980.

\section{Parte: Propuesta de revisión del Capítulo 3, MORTEROS de la Norma Básica MV 201-1972}

\subsection{Condiciones de los materiales}

Los materiales empleados en la fabricación de morteros cumplirán las condiciones que se definen a continuación: Cementos: 3.1.1. Cales aéreas: 3.1.2. Cales hidráulicas: 3.1.3. Arenas: 3.1.4. Aguas: 3.1.5. Aditivos: 3.1.6.

Además de estas condiciones se cumplirán en cada caso las que se especifiquen en las Prescripciones Técnicas Particulares del Proyecto. 


\subsubsection{Cementos}

El cemento empleado en cada caso será del tipo y categoria que se especifique en las Prescripciones Técnicas Particulares del Proyecto, pudiendo ser cualquiera de los que define el Pliego RC-75, Prescripciones Técnicas Generales para la Recepción de Cementos, a excepción del cemento aluminoso cuyo uso se prohibe. Para la elección del tipo y categoría pueden seguirse las recomendaciones del artículo A.1 del Apéndice A.

Los cementos empleados cumplirán todas las condiciones que para su tipo y categoria se imponen en el Pliego RC-75. De cada partida que llegue a obra se tomará una muestra, en las condiciones indicadas en el epigrafe 5 del Pliego RC-75, y que se conservará en envase etiquetado como en él se indica, el tiempo que ordene el Director de Obra, con objeto de poder ser ensayada si fuese preciso.

El suministro puede efectuarse a granel, almacenándose en silos o recipientes que lo aislen de la humedad. $\mathrm{O}$ en sacos, que llegarán a obra con etiqueta y precinto de fábrica, y se almacenarán en sitio ventilado y defendido de la intemperie y de la humedad del suelo y de las paredes. Vendrá acompañado de documentos de origen que indiquen tipo y categoría del cemento, y garantía del fabricante. Estos documentos se archivarán por el constructor.

El control se efectuará según lo indicado en el Capitulo 7 .

Si la temperatura del cemento al llegar a obra fuese superior a $70^{\circ} \mathrm{C}$, se comprobará antes de emplearlo, que no tiene tendencia a experimentar falso fraguado, realizando el ensayo mediante la Norma UNE (A).

Cuando el periodo de almacenamiento de un cemento haya sido superior a 30 dias, se realizará el ensayo de fraguado y el de resistencia mecánica a tres y siete días, sobre una muestra representativa del cemento, incluyendo los terrones si se hubiesen formado. Si los resultados de estos ensayos no cumpliesen las condiciones del Pliego RC-75, podrán realizarse ensayos para determinar la resistencia del mortero a 28 días según el Capitulo 7 , y estos resultados serán decisivos para aceptar o rechazar dicho cemento.

\subsubsection{Cal aérea}

La cal aérea empleada en la fabricación de morteros será cal apagada, generalmente en polvo, a veces en pasta. Amasada con agua endurece por carbonatación, al combinarse el hidróxido cálcico con el anhidrido carbónico del aire, y no endurece bajo el agua. Puede emplearse cal viva, en terrón o en polvo, convirtiéndola previamente en cal apagada en pasta.

La cal aérea puede ser de los tipos CA.1 y CA.2, definidos por las condiciones que se especifican en la Tabla 3.1.

El suministro de la cal aérea puede efectuarse a granel, almacenándose en silos o recipientes que la aislen de la humedad y de las corrientes de aire. $\mathrm{O}$ en sacos, que se almacenarán en sitio seco y resguardado de las corrientes de aire. Vendrá acompañado de documentos de origen, que indiquen tipo, y garantía del fabricante. Estos documentos se archivarán por el constructor.

El control se efectuará según lo indicado en el Capitulo 7.

\subsubsection{Cal hidráulica}

La cal hidráulica, que amasada con agua endurece bajo el agua, puede ser de los tipo $\mathrm{CH}-2$ y $\mathrm{CH}-5$, definidos por las condiciones que se exigen en la Tabla 3.2 . 
El suministro puede efectuarse a granel, almacenándose en silos o recipientes que la aislen de la humedad y de las corrientes de aire. $\mathrm{O}$ en sacos, que llegarán a obra con etiqueta y precinto de fábrica, y que se almacenarán en sitio seco y resguardado de corrientes de aire. Vendrá acompañado de los documentos de origen que indiquen tipo y garantía del fabricante. Estos documentos se archivarán por el constructor.

El control se efectuará según lo indicado en el Capítulo 7.

T ABLA 3.1

Condiciones de las cales aéreas para morteros

\begin{tabular}{|c|c|c|c|}
\hline \multirow{2}{*}{$\begin{array}{l}\text { Normas de } \\
\text { ensuyo }\end{array}$} & \multirow[t]{2}{*}{ Caracteristicas } & \multicolumn{2}{|c|}{ Condición exigible on el tipe } \\
\hline & & CA.1 & $\mathrm{CA} .2$ \\
\hline UNE 7095 & Oxido cálcico y magnésico (1) & $290 \%$ & $\geq 60 \%$ \\
\hline UNE 7099 & Fnhśarido carbónico (1) & $5 \%$ & $\leq 10 q$ \\
\hline UNE $7187(2)$ & Finura: & & \\
\hline UNE $7190(3)$ & Residuo en el tamiz 0,2 & $\leq 5 \%$ & $\leq 15 \%$ \\
\hline & Kesiduo en el tamiz 0,08( 4 ) & $\leq 15 \%$ & $\leq 50 \%$ \\
\hline
\end{tabular}

(1) Contenido referido al peso total menos el peso del agua cortenida, determinada según 7099.

(2) Tamizado en hlmedo para cal apajacia en pasta.

(3) Tamizado er seco para cal apagada en polvo.

(4) Corresponde al valor acumulado con el del tamiz 0,2

T A B LA 3.2

Condiciones de las cales hidráulicas

\begin{tabular}{|c|c|c|c|}
\hline \multirow{2}{*}{$\begin{array}{l}\text { Normas de } \\
\text { ensayo }\end{array}$} & \multirow[t]{2}{*}{ Caracteristicas } & \multicolumn{2}{|c|}{ Condiciones exigibles al tipo } \\
\hline & & $\mathrm{CH}-2$ & CH -5 \\
\hline UNE 7095 & $\begin{array}{l}\text { Srlice soluble + óxido fé - } \\
\text { rrico + oxido aluminico }\end{array}$ & $\geq 10 \%$ & $\geq 20 \div$ \\
\hline UNE 7099 & Anhíarido carbónico & $\leq 5 \varsigma_{0}$ & $\leq 5 \%$ \\
\hline UNE 7190 & $\begin{array}{l}\text { Finura: } \\
\quad \text { Residuo en tamiz } 0,2 \\
\quad \text { Residuo en tamiz } 0,08 \text { (1) }\end{array}$ & $\begin{array}{l}\leq 10 \% \\
\leq 30 \%\end{array}$ & \begin{aligned}$\leq & 5 \% \\
\leq 20 & \multicolumn{5}{c}{}\end{aligned}$ \\
\hline UNE 7203 & $\begin{array}{l}\text { Fracjuado: } \\
\quad \text { Comienzo } \\
\text { "leminación }\end{array}$ & $\begin{array}{l}2 \mathrm{~h} \\
\leq 48 \mathrm{~h}\end{array}$ & $\begin{array}{l}\geq 2 \mathrm{~h} \\
\leq 48 \mathrm{~h}\end{array}$ \\
\hline UND $\quad(B)$ & Expansiön por agujas & $\leq 10 \mathrm{~mm}$ & $\leq 10 \mathrm{~mm}$ \\
\hline \multirow[t]{2}{*}{ UNE $\quad(C)$} & \multirow{2}{*}{$\begin{array}{l}\text { Resistencia a } 28 \text { días } \\
\text { A flexotracción } \\
\text { A compresión }\end{array}$} & $\mathrm{kp} / \mathrm{cm}^{2}$ & $\mathrm{kp} / \mathrm{cm}^{2}$ \\
\hline & & $\begin{array}{l}0,5 \\
2\end{array}$ & $\frac{1}{5}, 5$ \\
\hline
\end{tabular}




\subsubsection{Arenas}

Pueden emplearse arenas naturales procedentes de rio, mina o playa, sometidas a lavado y, o, cribado cuando sea necesario; arenas de machaqueo de rocas sanas; o mezcla de ambas, en proporción definida.

Las arenas tendrán granos de forma poliédrica o redondeada, siendo rechazables las que los tengan predominantemente de forma de laja o acicula.

La arena empleada, o en su caso la mezcla de arenas en la proporción establecida, cumplirá las condiciones de la Tabla 3.3.

Las arenas se almacenarán en áreas, de modo que queden protegidas de contaminaciones por el ambiente y por el terreno. Cuando sea preciso se cubrirán las áreas, para evitar exceso de temperatura o de humedad.

TABLA 3.3

Condiciones de las arenas

\begin{tabular}{|c|c|c|}
\hline $\begin{array}{l}\text { Norma de } \\
\text { ensayo }\end{array}$ & Caracteristicas & $\begin{array}{l}\text { Condiciones } \\
\text { exigibles }\end{array}$ \\
\hline UNE 7139 & $\begin{array}{l}\text { Tamaño de los granos: } \\
\text { Retención en el tamiz } 2,5 \text { Uive } 7050 \\
\text { El resto de condiciones se refiere a la } \\
\text { fracción de arena que pasa por este tamiz }\end{array}$ & $\leq 10 \%$ \\
\hline UNE 7135 & Finos, determinados por levigación: $\bar{r}$ & $\mathrm{~F} \leq 10 \delta$ \\
\hline UNE 7324 & Equivalente de arena: E & $\sigma F+E \geq 70$ \\
\hline \multirow[t]{5}{*}{ UNE 7139} & $\begin{array}{l}\text { Granulometría, sobre la muestra levigacia: } \\
\text { Paso en on peso, por tamiz UNE } 7050: 2,5\end{array}$ & 100 \\
\hline & 1,25 & $\leq 100 \geq 60$ \\
\hline & 0,63 & $\leq 100 \geq 30$ \\
\hline & 0,32 & $\leq 60$ \\
\hline & 0,16 & $\leq 30 \geq 0$ \\
\hline UNE 7082 & Materia orgánica & $\begin{array}{l}\text { Colur no mas } \\
\text { oscuro que la } \\
\text { solución tipo }\end{array}$ \\
\hline UNE 7245 & Compuestos de azliLre, expresados en $\mathrm{SO}_{4}^{-}$ & $\leq 1,2 \%$ \\
\hline UNE 7137 & $\begin{array}{l}\text { Reactividad potencial con slcalis del cemento: } \\
\text { Concentracion de SiO: : S } \\
\text { Reducción de alcalinidad: } \mathrm{R}\end{array}$ & $S \leq 35+0,5 R \ngtr R$ \\
\hline
\end{tabular}

\subsubsection{Aguas}

Para el amasado del mortero, y el humedecimiento de los ladrillos, se admiten todas las aguas potables, y las sancionadas como aceptables por la práctica.

Cuando no se posea antecedentes de su utilización, o en el caso de duda, el agua cumplirá las condiciones de la Tabla 3.4. 
T A B LA 3.4

Condiciones del agua

\begin{tabular}{|c|c|c|c|}
\hline \multicolumn{2}{|c|}{$\begin{array}{l}\text { Norma de } \\
\text { ensayo }\end{array}$} & \multirow{2}{*}{$\begin{array}{l}\text { Caracteristicas } \\
\text { Toma de muestras }\end{array}$} & $\begin{array}{l}\text { Condicion } \\
\text { exigible }\end{array}$ \\
\hline UNE & 7236 & & \\
\hline UNE & 7234 & Exponente de hidrógeno pH & $5 \mathrm{~g} / \mathrm{l}$ \\
\hline UNE & 7130 & Sustancias disueltas & $\leq 15 \mathrm{~g} / 1$ \\
\hline UNE & 7131 & Compuestos de azufre, expresados en $\mathrm{SO}_{4}=$ & $\leq 1 \mathrm{~g} / 1$ \\
\hline UNE & 7178 & Cloruros, expresados en $\mathrm{Cl}^{-}$ & $6 s / 1$ \\
\hline UNE & 7235 & Sustancias orgánicas solubles en éter & $\leq 15 \mathrm{~g} / \mathrm{l}$ \\
\hline UNE & 7132 & Hidratos de carbono & 0 \\
\hline
\end{tabular}

Si no cumpliese alguna condición, como en el caso de aguas de mar o salinas, el Director de Obra puede autorizar su empleo si se justifica experimentalmente que no se alteran las propiedades exigidas al mortero.

\subsubsection{Aditivos}

Para mejorar la plasticidad del mortero fresco pueden emplearse aditivos plastificantes que posean el correspondiente Documento de Idoneidad Técnica, o sobre los que se tenga experiencia suficiente. Para modificar otras propiedades del mortero fresco o endurecido: plazos de fraguado, impermeabilidad, color, etc., pueden emplearse aditivos apropiados con las condiciones anteriores.

Se utilizarán los aditivos especificados en las Prescripciones Técnicas Particulares del Proyecto, con la dosificación y condiciones de empleo que en él figuren.

El Constructor puede proponer el empleo de aditivos no especificados en dichas Prescripciones, justificando la dosificación y condiciones de empleo mediante Documento de Idoneidad Técnica o datos experimentales fehacientes. Para su empleo se requiere autorización expresa del Director de Obra.

\subsection{Características de los morteros}

En el proyecto de un edificio se especificarán las características exigibles a cada mortero según 3.2.1. En el mortero fresco se definirá la plasticidad según 3.2.2, y la hidrofilia según 3.2.3. En el mortero fraguado se define la resistencia según 3.2 .4 , y la anheladicidad según 3.2.5.

\subsubsection{Especificación del mortero}

En las Prescripciones Técnicas Particulares del Proyecto para cada mortero empleado, se especificará:

El tipo: M20, M10, M5 ó M2, función de su resistencia (3.2.4).

El conglomerante o conglomerantes empleados, y sus contenidos mínimos, en $\mathrm{kg}$ por metro cúbico de mortero fresco. 
Eventualmente además el aditivo o aditivos prescritos, y su dosificación en $\%$ del peso total de los conglomerantes.

Pueden especificarse además otras condiciones: plasticidad (3.2.2), hidrofilia (3.2.3), anheladicidad (3.2.5), adherencia al ladrillo, color, etc.

En cl articulo A.2 del Apéndice A figuran recomendaciones para fijar la especificación de los morteros.

\subsubsection{Plasticidad}

Propiedad del mortero fresco, de la que depende su aptitud para poder extender la tortada, restregar el ladrillo y rellenar completamente las juntas: tendeles y llagas. La plasticidad depende del contenido de finos de la mezcla seca, y de la consistencia del mortero.

Contenido de finos de la mezcla seca es la suma de los pesos de las fracciones de los conglomerantes y de la arena que pasan por el tamiz 0,08 UNE 7050, dividida por el peso total de aquellos. Según la plasticidad especificada se cumplirán las condiciones de la Tabla 3.5.

La plasticidad magra es en general inadecuada.

T A B LA 3.5

Contenido de finos de la mezcla seca

\begin{tabular}{|l|c|c|}
\hline \multirow{2}{*}{ Plasticidad } & \multicolumn{2}{|l|}{$\begin{array}{l}\text { Porcentaje minimo de finos de la mezcla seca } \\
\text { de un mortero. }\end{array}$} \\
\cline { 2 - 3 } & Sin aditivo plastificante & Con aditivo plastificante \\
\hline Grasa & $>25$ & $>20$ \\
Sograsa & 25 a 15 & 20 a 10 \\
Magra & $<15$ & $<10$ \\
\hline
\end{tabular}

Consistencia del mortero fresco es el escurrimiento en \%, medido en el ensayo con mesa de sacudidas, según la Norma UNE (D).

\subsubsection{Hidrofilia}

Propiedad del mortero fresco, opuesta a la perjudicial segregabilidad de sus componentes, que se mide por la relación entre las consistencias después y antes del ensayo de succión, según la Norma UNE (E), que se realiza sobre una muestra de mortero fresco colocada en un molde cilindrico de $20 \mathrm{~mm}$ de altura, con fondo perforado de $170 \mathrm{~mm}$ de diámetro, sometida a una succión por vacio de $0,07 \mathrm{kp} / \mathrm{cm}^{2}$ durante 60 segundos.

\subsubsection{Resistencia}

Los morteros para fábricas de ladrillo pueden ser de los cuatro tipos definidos en la Tabla 3.6, según su resistencia a flexotracción y a compresión a edad de 28 dias, medida sobre probetas de $4 \times 4 \times 16 \mathrm{~cm}^{3}$, conservadas en aire con más de $90 \%$ de humedad relativa, a $21 \pm 2^{\circ} \mathrm{C}$, según la Norma UNE (F), ensayadas según la Norma UNE (G). 
TABLA 3.6

Tipos de mortero

\begin{tabular}{|c|c|c|c|c|c|}
\hline \multirow{3}{*}{ Tipo } & \multicolumn{4}{|c|}{ Resistencia a 28 días a } & \multirow{3}{*}{$\begin{array}{l}\text { Nivel de } \\
\text { control } \\
\text { exigido }\end{array}$} \\
\hline & \multicolumn{2}{|c|}{ Flexotraccion } & \multicolumn{2}{|c|}{ Compresión } & \\
\hline & $\mathrm{MPa}$ & $\mathrm{kp} / \mathrm{cm}^{2}$ & $1.1 \mathrm{~Pa}$ & $\mathrm{kp} ; \mathrm{cm}^{2}$ & \\
\hline 1.120 & 4,5 & 46 & 20 & 204 & Normal. \\
\hline 1110 & 3,0 & 31 & 10 & 102 & Normal \\
\hline M5 & 1,5 & 15 & j & 51 & Segin P.T.F. \\
\hline M2 & 0,8 & 8 & 2,5 & 26 & Reciucicio \\
\hline
\end{tabular}

En la Tabla 3.6 se indica además el nivel de control que, según el Capitulo 7, se exige para cada tipo. En el tipo M5, si las Prescripciones Técnicas Particulares de Proyecto no exigen control a nivel normal, se entiende que es a nivel reducido.

\subsubsection{Anheladicidad}

Cuando se especifique que un mortero sea anheladizo, la comprobación se efectuará según la Norma UNE (H). Después de 20 ciclos de congelado y deshielo las probetas de mortero no tendrán grietas ni desconchados, y la pérdida de peso no será superior al $3 \%$.

\subsection{Confección de los morteros}

La dosificación de cada mortero se determinará según 3.3.1. El amasado se ejecutará según 3.3.2, y el tiempo de utilización del mortero amasado se limitará según 3.3.3.

\subsubsection{Dosificación del mortero}

En cada obra, antes de comenzar la ejecución de las fábricas, se determinará experimentalmente la dosificación de la mezcla, de modo que el mortero fresco, y el endurecido, cumplan todas las condiciones de la especificación.

Según el sistema de medición de que se disponga para la amasadora de mortero en la obra, la dosificación de los componentes en la mezcla se establecerá en partes en peso o en partes en volumen. En el Artículo 1.3, Apéndice A, se dan indicaciones para determinar la dosificación.

\subsubsection{Amasado del mortero}

El amasado del mortero se realizará según lo establecido en las Prescripciones Técnicas Particulares del Proyecto. En la amasadora u hormigonera se batirán todos los componentes del mortero cl tiempo necesario para conseguir la uniformidad de la mezcla, como minimo 1 minuto. Si se autorizase el amasado a mano, se hará sobre una plataforma impermeable y limpia, efectuándose como mimino tres batidos.

Cuando se emplee amasadora u hormigonera, con ésta en marcha, el orden de vertido será: parte 
del agua de amasado, en su caso con el aditivo incorporado, la arena, el cemento, en su caso la cal apagada en polvo o pasta, y finalmente el resto del agua de amasado.

Cuando se efectúe a mano el conglomerante o conglomerantes en polvo se mezclarán en seco con la arena, y después se añadirá el agua, en su caso con el aditivo incorporado. Si se emplea cal apagada en pasta, ésta se verterá sobre la mezcla en seco, y se añadirá después el agua.

\subsubsection{Tiempo de utilización}

El plazo de utilización del mortero fresco, medido desde el comienzo del amasado, será el que se especifique en las Prescripciones Técnicas Particulares del Proyecto, que en general no será superior a dos horas.

Cuando en la fabricación del mortero se emplee un aditivo retardador del fraguado, el plazo de utilización podrá ser mayor de dos horas. Este plazo determinará mediante resultados experimentales, que justifiquen que el mortero mantiene las propiedades especificadas a pesar de haberse ampliado el plazo.

Durante el plazo de utilización se prohibe agregar agua de mortero mediante rebatido. Transcurrido el plazo de utilización, el mortero sobrante se desechará sin intentar volver a hacerlo utilizable.

\section{APENDICE A. RECOMENDACIONES PARA LOS MORTEROS}

\section{A.1. Elección del cemento}

En las Prescripciones Técnicas Particulares del Proyecto debe figurar el tipo y categoria del cemento que se empleará en la confección de los morteros, haciéndose la elección por razones económicas y funcionales, pudiendo servir de orientación las recomendaciones de la Tabla A.1.

\section{A.2. Especificación del mortero}

En las Prescripciones Técnicas Particulares del Proyecto, para cada uno de los morteros que se emplearán en la ejecución de las fábricas de ladrillo de la obra, se especificará el tipo: M20, M10, M5 ó M2 utilizable. Este se define por su resistencia a compresión a 28 dias (3.2.4), que debe ser proporcionada a la resistencia a compresión del ladrillo empleado con dicho mortero en la ejecución de la fábrica. La resistencia del mortero en general es suficiente que sea igual a la mitad de la resistencia a compresión del ladrillo y, salvo excepciones, no debe ser superior a ésta, dándose indicaciones en la Tabla A.2.

Influyen también decisivamente las condiciones de la fábrica: clase de ladrillo, terminación de los paramentos, misión estructural y situación, dándose indicaciones en la Tabla A.3.

Se especificará también el contenido mimino del conglomerante o conglomerantes que deban emplearse. Se dan indicaciones para ello en la Tabla A.4.

Las especificaciones de la dosificación de aditivos, cuando se establezca su empleo, se redactarán siguiendo los correspondientes Documentos de Idoneidad Técnica, o la experiencia adquirida sobre su empleo.

La especificación de la anheladicidad es importante en morteros para fábricas vistas que vayan en contacto con el terreno, o el agua, o a la intemperie en zonas de clima frio. 
T A B LA A. 1

Recomendaciones para uso de cementos en morteros para fábricas de ladrillo

\begin{tabular}{|c|c|c|}
\hline \multicolumn{2}{|c|}{ Cementos } & \multirow{2}{*}{ Recomendaciones de uso } \\
\hline Tipo & Categoria & \\
\hline \multirow{2}{*}{ Iortland } & $P-350$ & Uso aconscjable, cuando sea viable \\
\hline & $\begin{array}{l}P-450 \\
P-550\end{array}$ & Uso no aconsejable, pero posible \\
\hline \multirow{2}{*}{$\begin{array}{l}\text { Portlind } \\
\quad \text { con } \\
\text { adiciones } \\
\text { activas }\end{array}$} & $P A-350$ & Uso aconsejable, actualmente el más generalizado \\
\hline & $\begin{array}{l}P A-450 \\
P A-550\end{array}$ & Uso no aconsejable, pero posible \\
\hline \multirow[t]{2}{*}{$\begin{array}{l}\text { Sicierur- } \\
\text { gico }\end{array}$} & $\begin{array}{l}S-I-350 \\
S-I I-350 \\
S-I I I-250 \\
S-I I I-350\end{array}$ & $\begin{array}{l}\text { Uso posible. Aconsejable en ambientes maritimos. } \\
\text { Existe peligro de desigualdades de coloración en } \\
\text { los morteros. }\end{array}$ \\
\hline & $S-I-450$ & Uso no aconsejable, pero posible \\
\hline \multirow{3}{*}{ Puzolánioo } & $\begin{array}{l}\text { PUZ-I-250 } \\
\text { FUZ-I-350 }\end{array}$ & $\begin{array}{l}\text { Uso aconsejable, cuando sea viable. Los morteros } \\
\text { presentan mejor comportamiento a las aguas carbo } \\
\text { nicas. }\end{array}$ \\
\hline & EUZ-I-450 & Uso no aconse jable pero posible \\
\hline & $\begin{array}{l}P U Z-I I-250 \\
P U Z-I I-350 \\
P U Z-I I-450\end{array}$ & $\begin{array}{l}\text { Liso no aconsejable, pero posible. Existe peligro } \\
\text { de manchas eri las fábricas. }\end{array}$ \\
\hline Compuesto & $C-200$ & Podría usarse si so fabricase? \\
\hline Aluminoso & $A-550$ & Uso prohibido \\
\hline \multirow{2}{*}{ Natural } & $\begin{array}{l}N L-30 \\
N L-80\end{array}$ & $\begin{array}{l}\text { Uso posible. Se obticne baja resistencia. lio se } \\
\text { mezclara con otros cementus, salvo experimentacion }\end{array}$ \\
\hline & $N R-20$ & $\begin{array}{l}\text { Uso solo cll casos especiales, por la rapiciez de } \\
\text { su fraguado }\end{array}$ \\
\hline $\begin{array}{l}\text { Portland de } \\
\text { alta resis- } \\
\text { tencia ini- } \\
\text { cia: }\end{array}$ & $\begin{array}{l}P-350-A R I \\
P-450-A R I \\
P-550-A R I\end{array}$ & Uso no aconsejable \\
\hline \multirow[t]{2}{*}{$\begin{array}{l}\text { Portland } \\
\text { resisten- } \\
\text { te al ye- } \\
\text { so }\end{array}$} & $P-350-Y$ & $\begin{array}{l}\text { Uso aconsejable en fabricas en contacto con terre } \\
\text { nos yesiferos o aguas selenitosas, o en ambientes acjesivus } \\
\text { por compuestos de azufre }\end{array}$ \\
\hline & $\begin{array}{l}P-450-Y \\
P-550-Y\end{array}$ & Uso no aconsejable, pero posible \\
\hline $\begin{array}{l}\text { Portland de } \\
\text { bajo calor de } \\
\text { hidratación }\end{array}$ & $\mathrm{P}-350-\mathrm{BC}$ & Usc no aconsejable, por razón de coste \\
\hline \multirow{2}{*}{$\begin{array}{l}\text { Portland } \\
\text { blanco }\end{array}$} & $P-350-B$ & $\begin{array}{l}\text { Uso aconsejable para coloraciones ciaras de los } \\
\text { morteros, s6lo o mezclado con p-350 o in-350 }\end{array}$ \\
\hline & $\begin{array}{l}P-450-B \\
P-550-B\end{array}$ & Uso no aconsejable, pero posible \\
\hline $\begin{array}{l}\text { Compues to } \\
\text { blanco }\end{array}$ & $C-200-B$ & Podría usarse si se fabricase \\
\hline
\end{tabular}

\section{A.3. Dosificación de los morteros}

Bajo la supervisión de la Dirección de Obra, y antes de comenzar la ejecución de las fábricas, el 
constructor establecerá la dosificación de la mezcla para conseguir un mortero que cumpla con las condiciones exigidas en esta Norma y en las Prescripciones Técnicas Particulares del Proyecto. Esto se efectuará en la obra, o se encargará a un Laboratorio Oficial u homologado.

Se empleará para la mezcla cemento, y en su caso cal, de los tipos y categorias especificados, y arena cuyas características sean conocidas mediante ensayos realizados por el suministrador, o, en su defecto, encargados para la obra, y que cumplan lo exigido en 3.1.5.

TABLA A. 2

Tipo de mortero según el tipo de ladrillo

\begin{tabular}{|c|c|c|c|c|c|}
\hline \multicolumn{2}{|c|}{ Lacirillo } & \multicolumn{4}{|c|}{ l'ipo de mortero } \\
\hline Clase & $\begin{array}{c}\text { Resistencia } \\
\text { Mpa }\end{array}$ & 112 & M5 & $\$ 110$ & 120 \\
\hline \multirow[t]{3}{*}{ Hiveco } & 3 & $\mathrm{R}$ & - & - & - \\
\hline & 5 & $\mathrm{R}$ & $\mathrm{P}$ & - & - \\
\hline & 7 & $\mathrm{R}$ & $\mathrm{P}$ & - & - \\
\hline \multirow[t]{4}{*}{ Macizo } & 10 & $\mathrm{P}$ & $\mathrm{R}$ & $\mathrm{P}$ & - \\
\hline & 15 & $\mathrm{P}$ & R & $\mathrm{P}$ & - \\
\hline & 20 & - & F & $\mathrm{R}$ & $\mathrm{P}$ \\
\hline & 30 & _ & - & $\mathrm{P}$ & $\mathrm{R}$ \\
\hline
\end{tabular}

T ABLA A. 3

Tipo de mortero según las características de la fábrica

\begin{tabular}{|c|c|c|c|c|}
\hline \multicolumn{4}{|c|}{ Caracteristicas de la fabrica } & \multirow{2}{*}{$\begin{array}{l}\text { Tipo de } \\
\text { mortero }\end{array}$} \\
\hline $\begin{array}{l}\text { Clase de } \\
\text { ladrillo }\end{array}$ & Paramentos & Estructural & Situación & \\
\hline Hueco & Revestidos (1) & No $\sigma \mathrm{Si}$ & Interior o exterior & $\mathrm{M} 2$ \\
\hline \multirow{4}{*}{ Macizo } & \multirow[t]{2}{*}{ Revesticios (1) } & No & Interior o exterior & $\mathrm{M} 2$ \\
\hline & & $\mathrm{Si}$ & Interior c exterior & $\$ 15$ \\
\hline & \multirow[t]{2}{*}{ Vistos } & No & $\begin{array}{l}\text { Interior } \\
\text { Exterior }\end{array}$ & $\begin{array}{l}112 \\
1110\end{array}$ \\
\hline & & $\mathrm{Si}$ & $\begin{array}{l}\text { Interior } \\
\text { Exterior } \\
\text { Contacta terreno o água }\end{array}$ & $\begin{array}{l}M 5 \\
M 10 \\
M 20\end{array}$ \\
\hline $\begin{array}{l}\text { (1) Efect } \\
\text { chap }\end{array}$ & $\begin{array}{l}\text { amente reve } \\
\text { de piedra, }\end{array}$ & $\begin{array}{l}\text { estidos, con } \\
\text { prefabric }\end{array}$ & $\begin{array}{l}\text { enfoscado o revoco im } \\
\text { ados de hormigón, plaq }\end{array}$ & $\begin{array}{l}\text { neable, } \\
\text { as, etc. }\end{array}$ \\
\hline
\end{tabular}


TABLA A.4

Contenidos minimos de conglomerantes

\begin{tabular}{|c|c|c|c|}
\hline \multirow{2}{*}{ Tipo de mortero } & \multicolumn{3}{|c|}{ Contenicios minimos de conglomerante, en $\mathrm{kg} / \mathrm{m}^{3}$} \\
\cline { 2 - 4 } & Cemento PA 350 & $\begin{array}{c}\text { Cal aérea apaga- } \\
\text { da en polvo (1) }\end{array}$ & $\begin{array}{c}\text { Cal Hidrálica } \\
\text { CH-2 (2) }\end{array}$ \\
\hline M20 & 400 & - & \\
\hline M10 & 300 & 100 & 300 \\
\hline M5 & 250 & 150 & \\
\hline M2 & 200 & (1) Contenido mínimo que conviene exigir además del del cemento \\
& PA 350 cuando el contenido de finos de la arena es bajo. \\
\hline (2) En mortero cuyo conglomerante unico sea cal hidráulica.
\end{tabular}

T ABLA A.5

Orientaciones para la dosificación de las mezclas de prueba con cemento PA-350

\begin{tabular}{|c|c|c|c|c|c|c|}
\hline \multirow{2}{*}{$\begin{array}{l}\text { Tipo de } \\
\text { mortero }\end{array}$} & \multicolumn{3}{|c|}{ Dosificación, partes en peso } & \multicolumn{3}{|c|}{ Dosificación, partes en volumen } \\
\hline & $\begin{array}{l}\text { Cemento } \\
P A-350\end{array}$ & $\begin{array}{l}\text { Cal aérea } \\
\text { apagada en } \\
\text { polvo }\end{array}$ & Arend & $\begin{array}{l}\text { Cemerto } \\
P A-350\end{array}$ & $\begin{array}{l}\text { Cal abred } \\
\text { apacacia en } \\
\text { poivo }\end{array}$ & Arena \\
\hline$M 20$ & 1 & - & $3-3,5$ & 1 & - & $2,25-3$ \\
\hline M10 & $\begin{array}{l}1 \\
1\end{array}$ & $\frac{-}{0,2}$ & $\begin{array}{c}4-5 \\
4,5-5,5\end{array}$ & $\begin{array}{l}1 \\
1\end{array}$ & $\begin{array}{c}- \\
0,4-0,6\end{array}$ & $\begin{array}{c}3-4 \\
3,5-4,5\end{array}$ \\
\hline 115 & $\begin{array}{l}1 \\
1\end{array}$ & $\frac{-}{0,4}$ & $\begin{array}{l}5,5-6,5 \\
6-7\end{array}$ & $\begin{array}{l}1 \\
1\end{array}$ & $\begin{array}{c}- \\
0,8-1,2\end{array}$ & $\begin{array}{c}4-5 \\
4,5-5,5\end{array}$ \\
\hline $\mathrm{M} 2$ & $\begin{array}{l}1 \\
1\end{array}$ & $\begin{array}{l}- \\
1\end{array}$ & $\begin{array}{l}7-8 \\
8-9\end{array}$ & $\begin{array}{l}1 \\
1\end{array}$ & $\begin{array}{c}- \\
2,3\end{array}$ & $\begin{array}{c}5.5-6,5 \\
6-7\end{array}$ \\
\hline
\end{tabular}

Es usual la práctica de establecer la dosificación en volumen, midiendo los componentes en recipientes adecuados. Puede disponerse de una instalación que mida los componentes en peso. La dosificación se establecerá en volumen o en peso según el sistema de medición de que se disponga.

Se realizarán mezclas de prueba con diferentes dosificaciones, agregando el agua necesaria para obtener la plasticidad deseada. Mediante un recipiente de volumen conocido y una báscula, se determinará el contenido de cemento, y en su caso el de cal, por metro cúbico.

Si la especificación exige resistencias, lo que es preceptivo siempre en los morteros M20 y M10, y a veces en el mortero M5, con cada mezcla de prueba se llenará un molde de tres probetas de $4 \times 4 \times 16 \mathrm{~cm}^{3}$, que se ensayarán a flexotracción y compresión, a 28 dias, en obra o enviándolas al Laboratorio. 
Si el Pliego de Prescripciones Particulares del Proyecto exigiese otras propiedades se hará su determinación en Laboratorio con cada mezcla de prueba.

Realizados los ensayos, el constructor elegirá como dosificación la de una mezcla cuyos resultados cumplan todas las especificaciones.

Cuando se emplee cemento PA-350, pueden servir de orientación para establecer las dosificaciones de las mezclas de prueba los datos de la Tabla A.5.

Los valores de la Tabla A.5 son indicativos de la resistencia del mortero con arenas de buena calidad. Debe tenerse en cuenta que la clase de la arena puede influir mucho en la resistencia.

También debe señalarse que los morteros de tipo M5 y M2, salvo excepciones, son heladizos y que por consiguiente, si se requiere que el mortero sea anheladizo, debe especificarse un tipo de resistencia mayor.

Si se emplea cal hidráulica debe seguirse la experiencia local para establecer la dosificación de las mezclas.

Relación de Normas UNE que deben prepararse para el Capítulo 3. Morteros, de la nueva adición de la Norma MV 201.

UNE (A) Método de ensayo para determinar el falso fraguado del cemento $(\rightarrow 3.1 .1)$ (Puede adaptarse ASTM C451-75).

UNE (B) Determinación de expansividad de un conglomerante por el método de las agujas $(\rightarrow 3.1 .3)$ (Según RC-75.7.5).

UNE (C) Determinación de la resistencia a flexotracción y compresión de las cales hidráulicas $(\rightarrow 3.1 .3)$ (Adaptar UNE 7205).

UNE (D) Determinación de una resistencia de morteros mediante la mesa de sacudidas $(\rightarrow$ 3.2.2) (Separarla de la Norma UNE 7205).

UNE (E) Método de ensayo para determinar la hidrofilia de un mortero $(\rightarrow 3.2 .3)$ (Puede adaptarse ASTM C91-78.23 y ASTM C270 - 80a.11.1).

UNE (F) Fabricación y conservación de las probetas de mortero de albañilería $(\rightarrow 3.2 .4)$ (Con criterios análogos a los empleados en obra).

UNE (G) Determinación de la resistencia a flexotracción y compresión de los morteros de albañilería $(\rightarrow 3.2 .5)$ (Adaptar UNE 7205).

UNE (H) Ensayo de heladicidad para morteros de albañileria (Adaptar UNE 7062 y UNE 7070). 